Portland State University

PDXScholar

$1-1-2011$

\title{
Interception in Open-grown Douglas-fir (Pseudotsuga menziesii) Urban Canopy
}

\author{
Mitchell Bixby \\ Portland State University
}

Follow this and additional works at: https://pdxscholar.library.pdx.edu/open_access_etds

Part of the Environmental Sciences Commons, and the Forest Sciences Commons Let us know how access to this document benefits you.

\section{Recommended Citation}

Bixby, Mitchell, "Interception in Open-grown Douglas-fir (Pseudotsuga menziesii) Urban Canopy" (2011). Dissertations and Theses. Paper 37.

https://doi.org/10.15760/etd.37

This Thesis is brought to you for free and open access. It has been accepted for inclusion in Dissertations and Theses by an authorized administrator of PDXScholar. Please contact us if we can make this document more accessible: pdxscholar@pdx.edu. 
Interception in Open-grown Douglas-fir

(Pseudotsuga menziesii) Urban Canopy

by

Mitchell Bixby

A thesis submitted in partial fulfillment of the requirements for the degree of

\author{
Master of Science \\ in \\ Environmental Sciences and Resources \\ Thesis Committee \\ J. Alan Yeakley, Chair \\ Andrew Fountain \\ Joseph Maser
}

Portland State University

2011 


\begin{abstract}
I hypothesized that Douglas-fir trees (Pseudotsuga menziesii) standing apart from other trees ('open-grown') will intercept more rainfall than Douglas-fir trees standing near other trees ('closed-canopy'). Open-grown trees differ structurally and are more common in urban settings, yet have been infrequently studied. Existing literature, based primarily on closed-canopy trees, suggests Douglas-fir trees in Pacific Northwest forests intercept approximately $25 \%$ of rainfall annually. Because opengrown trees have more vertical leaf area than individual trees in closed-canopy forests, I expected to find higher interception by open-grown trees.

I collected throughfall under four open-grown Douglas-firs using six static collectors ('buckets') per tree, and two closed-canopy Douglas-firs using six buckets per tree. I compared their throughfall to the incident rainfall in two adjacent openfield buckets. Gross interception was measured in 53 collections during rainy weather from 16 Nov07 to 31 Mar08. Over the same period, rainfall per hour, wind speed, gust speed, wind direction, temperature and relative humidity were collected at a weather station located within $1 \mathrm{~km}$ of the site. For comparison, average hourly rainfall at Portland International Airport from 1950 to 2005, for the same months of the collection period, showed a comparable number of medium- to high-intensity storms, but more low-intensity storms.
\end{abstract}

I found that incident rainfall for the adjacent open-field buckets totaled $65.6 \mathrm{~cm}$ and $71.6 \mathrm{~cm}$ over the study period. Interception values for closed-canopy trees averaged $26 \%$, corresponding to the literature, with results of 22 and $30 \%$. 
Interception values for open-grown trees averaged 31\%, with results ranging from 15 to $45 \%$. Three of the 24 buckets returned overall negative interception rates over five months.

Given the lower storm intensity of 2007-08, interception rates may be somewhat high, compared to the historical average. The negative interception rates at three buckets were likely due to their locations under high drip points, as has been observed in other studies. Considering the wide range of canopy architecture among open-grown trees, the high variability in interception was not surprising. My hypothesis was supported by the data, but requires more testing to better generalize these results. Future studies that link open grown tree canopy morphological characteristics to interception are warranted. 


\section{Dedication}

For Becky-you were right. 


\section{Acknowledgements}

The designing, doing, reviewing and writing of this project was a collaboration, if not of a cast of thousands, of several dozen. Chief among them was Alan Yeakley. Many thanks, Alan, for believing in this project and in me. Here's to Cubs and Cards going out for beers together. Go C[ ]s!!

Also, my thanks to Andrew Fountain and Joe Maser, for their interest and contributions. This was perhaps an unusual ride, this thesis journey. Thanks for sticking with me.

Of course, a gigantic shout out goes to everyone from the lab: Kate, Ben, Robin, Adelaide, Noah, Sarah and particularly Josh. I couldn't have figured it all out without the peanut gallery. I think we laughed a little along the way, too.

At the same time, I am deeply indebted to Dan Moeller and all the great people at Hoyt Arboretum. Meaning all the people at Hoyt Arboretum. This project simply wasn't do-able without your support. Thank you for looking after all my baby blue buckets.

The support of Jennifer Goodridge, Paul Ketcham and James Allison at the Bureau of Environmental Services also played no small role in my completing this thesis. They recognized that the schedule juggling involved was, $\mathrm{mm}$, non-trivial and I am grateful for their understanding.

It's easy to see how acknowledgements could go on for pages, but the aid of Brett and Leah Schaerer really does require recognition. Brett was the ideal methods partner, with a legion of tricks and tools at his disposal. Leah, though, asked The Question: why not use a water bottle as bucket AND funnel? At which point Brett and I, buried in the wreckage of multiple futilities, both slapped our respective foreheads. Leah is the real genius behind it all.

Which leads inevitably to James and the folks at Culligan Water. Their willingness to help out in a really reasonable exchange allowed my rainfall collection to happen. It was new and it was weird but they heard me out and then played along. Thank you so much.

And, finally, a word of appreciation to everyone who kindly inquired how my thesis was (hi, Mom). It was fine. Really.

Now, it's better. Thanks for asking. 


\section{TABLE OF CONTENTS}

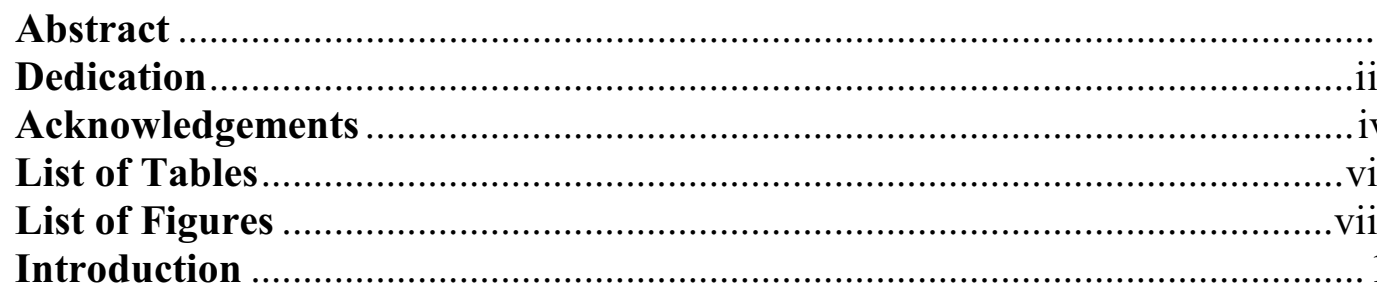

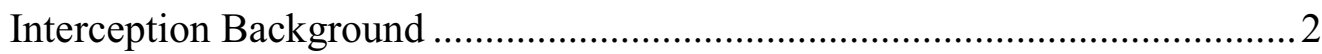

Closed-canopy v. open-grown …………........................................... 3

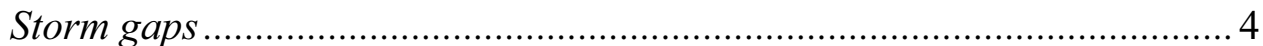

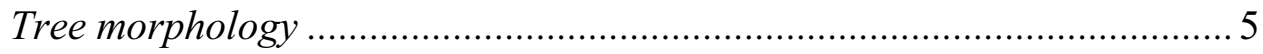

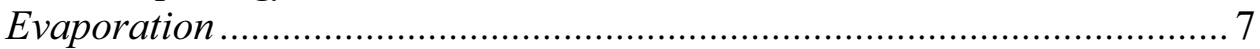

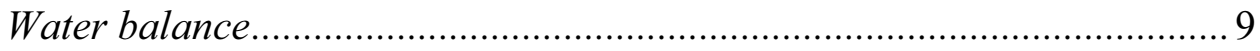

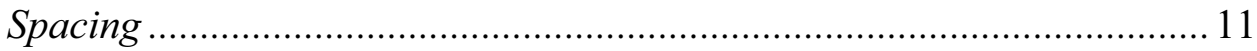

Wind

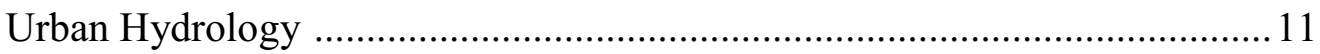

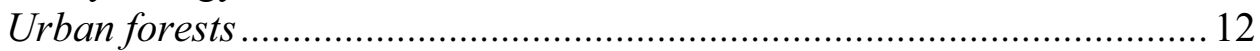

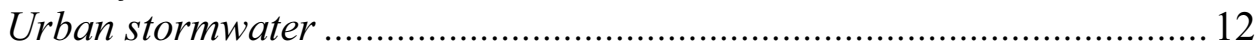

Reasons to Research Open-Grown Trees ...................................................... 14

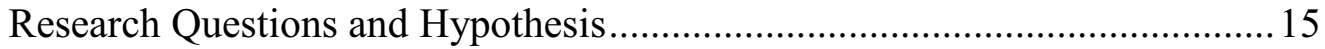

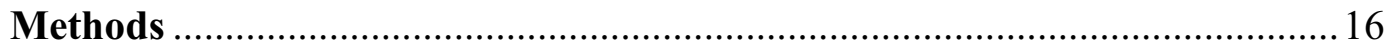

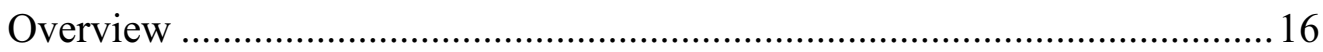

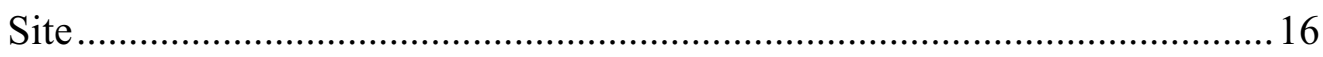

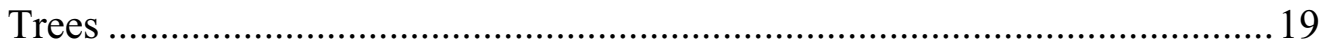

Open-grown

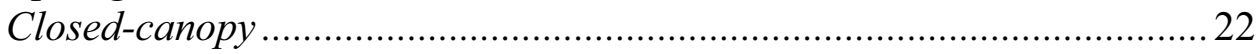

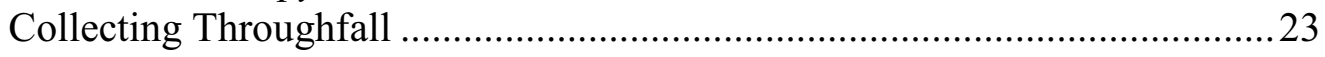

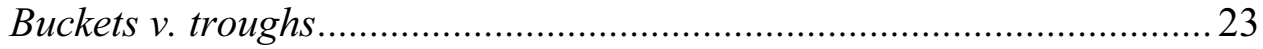

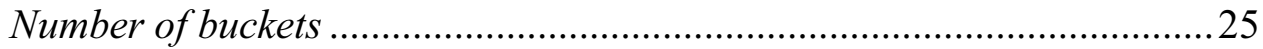

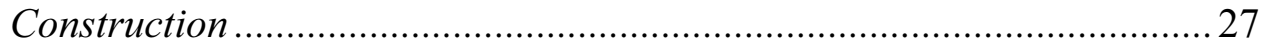

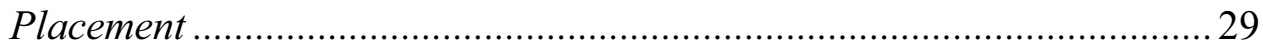

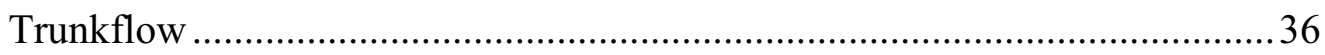

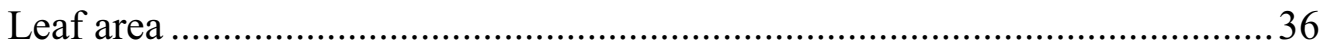

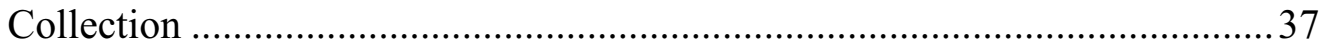

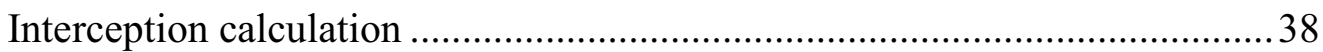

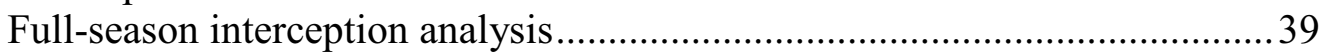

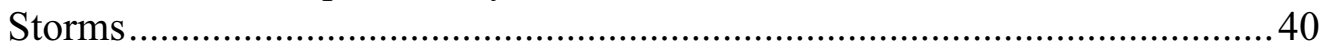

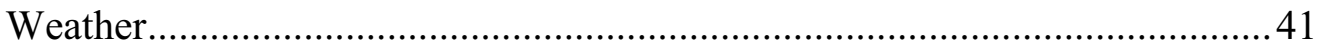

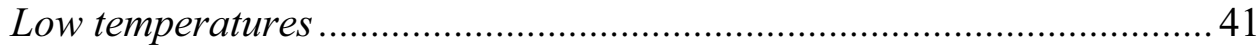

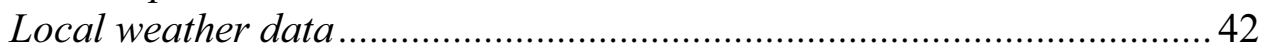

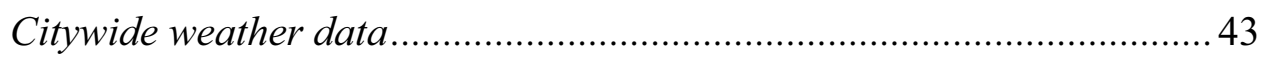

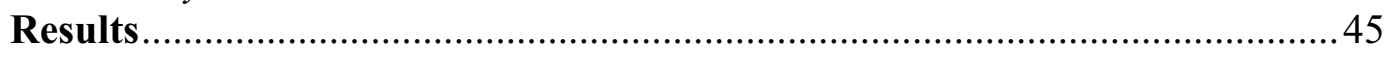

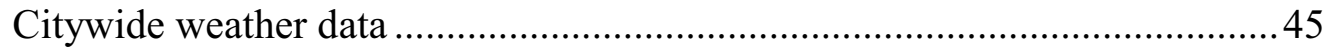

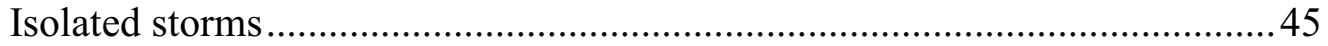




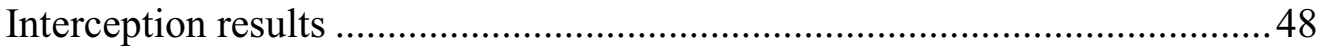

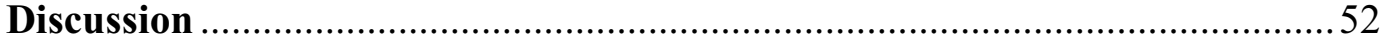

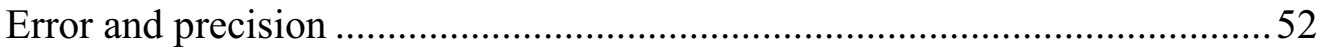

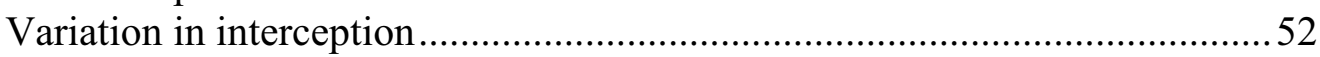

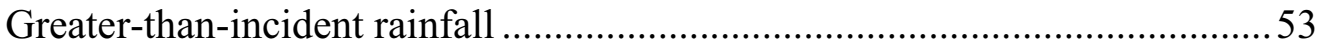

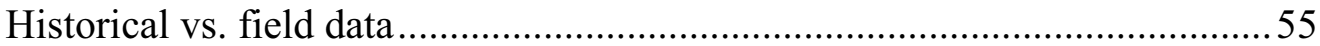

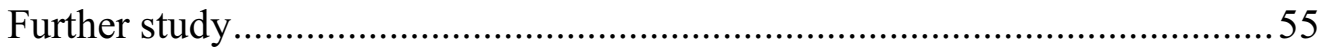

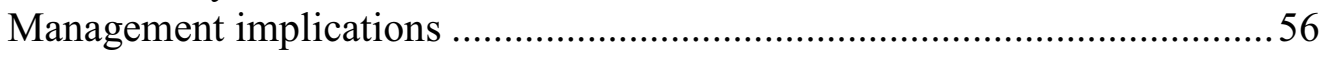

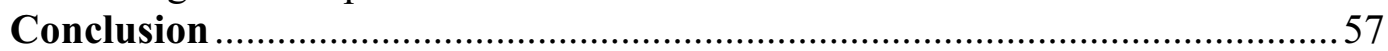

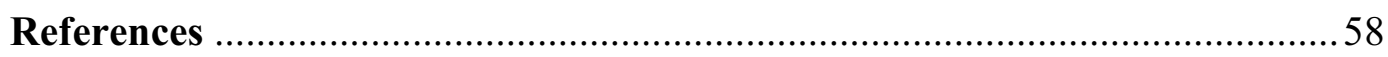

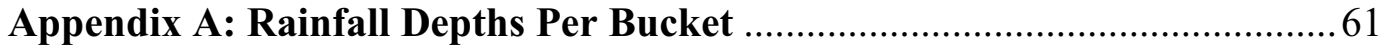

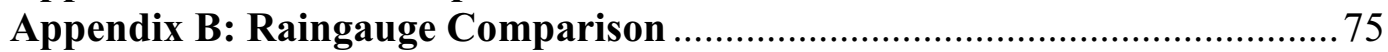




\section{List of Tables}

Table 1. Important Studies on Forest Interception. ....................................... 2

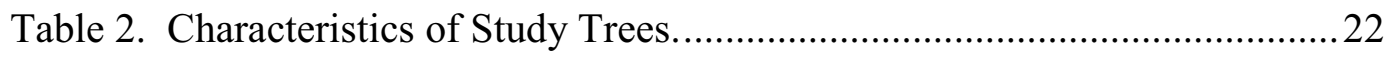




\section{List of Figures}

Figure 1. Map of Study Sites and Raingauges at Hoyt Arboretum in

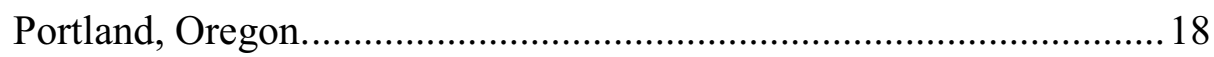

Figure 2. Photos of Open-grown Douglas-firs .................................................2

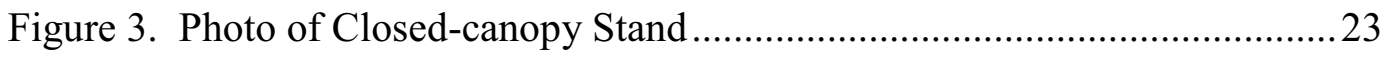

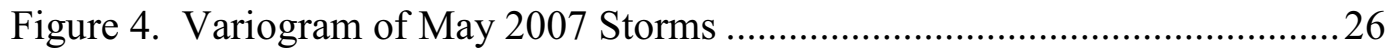

Figure 5. Schematic of a Sample Collection Bucket............................................28

Figure 6. Photo of Buckets at Study Tree 4......................................................2 28

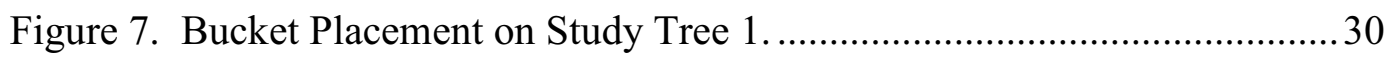

Figure 8. Bucket Placement on Study Tree 2 .................................................... 31

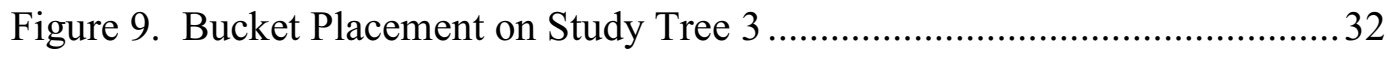

Figure 10. Bucket Placement on Study Tree 4 ....................................................33

Figure 11. Bucket Placement on Study Tree 5 ………......................................... 34

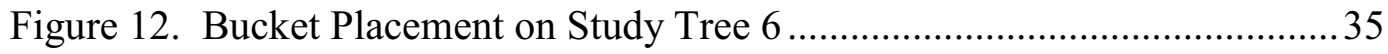

Figure 13. A Sample of Throughfall Data................................................................ 39

Figure 14. Comparison of Historic Storm Intensity ...........................................45

Figure 15. Sixteen Isolated Storms Compared by Intensity, Duration

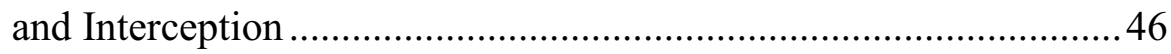

Figure 16. Average Wind Direction of Sixteen Isolated Storms .........................47

Figure 17. Average Wind Speed of Sixteen Isolated Storms ................................4 47

Figure 18. Average Relative Humidity of Sixteen Isolated Storms ......................48

Figure 19. Study-long Interception for Each Study Tree .....................................49 
Figure 20. Study-long Interception of Open-grown Trees ..............................50

Figure 21. Study-long Interception of Closed-canopy Trees ............................51 


\section{Introduction}

Studies of interception by tree canopy have been carried out for decades.

Beginning at least as far back as the eminent hydrologist R.E. Horton (1919), scientists have explored how tree canopy acts as a platform for rain, allowing it to evaporate and preventing it from reaching the ground ("interception"). Helvey and Patric (1965) began using regression models to describe interception data relationships, before Zinke (1965), Rutter et al. (1971), and Mulder (1985) shifted to more complex, process-based models.

Interception studies since the 1970s have focused almost exclusively on existing forests or plantations (Rutter et al. 1971, Gash 1979, Liu 2001, Pypker et al. 2005), which are structurally distinctive. Trees growing in these conditions ("closedcanopy") develop vertically shallower canopies, and lower interception capacity (Xiao et al. 2000a). Conversely, trees in cities are frequently found standing on their own, either along streets, or in yards, or in parks. These trees have grown sufficiently apart from other trees or other structures ("open-grown"). The result is often that they have full canopies and maximum branching, leading to high-light availability, and highevaporation capacity (Teklehaimanot et al. 1991).

Interception capacity of urban trees represents an important, and under-studied, component of urban hydrology. In the absence of natural forests, the larger canopies of open-grown urban trees may play a disproportionate role in managing the quantity and rate of rain entering an urban ecosystem. Also, from a practical standpoint, urban 
stormwater managers believe that tree canopy helps mitigate the growing runoff caused by the increasing hardscape of cities (McPherson et al. 1999, Xiao et al. 2000a, McPherson et al. 2005). The role of trees in urban hydrology and the quantification of their impact remains an important research question.

Interception Background

The combination of a large number of variables affecting interception with our inability to directly measure interception makes the description of rain/tree interactions complicated and difficult. Some key variables are brought out in the literature, of which several important studies are listed below in Table 1.

\begin{tabular}{|c|c|c|c|c|c|}
\hline Author & Year & Species & Location & Interception & Canopy \\
\hline Rothacher & 1963 & $\begin{array}{l}\text { Pseudotsuga } \\
\text { menziesii }\end{array}$ & W. Oregon, USA & $\begin{array}{l}24 \% \text { summer/ } \\
14 \% \text { winter* }\end{array}$ & Closed \\
\hline Rutter, et al. & 1970 & Pinus nigra & SE England, UK & $\sim 34 \%$ & Closed \\
\hline Gash & 1979 & Pinus sylvestris & East Anglia, UK & unknown & Closed \\
\hline $\begin{array}{l}\text { Teklehaimanot, et } \\
\text { al. }\end{array}$ & 1990 & Picea sitchensis & SE England, UK & unknown & Open \\
\hline Xiao, et al. & 1999 & $\begin{array}{l}\text { Pyrus } \\
\text { calleryana \& } \\
\text { Quercus suber }\end{array}$ & $\begin{array}{l}\text { Davis, California, } \\
\text { USA }\end{array}$ & 15 and $21 \%$ & Open \\
\hline $\begin{array}{l}\text { Price \& Carlyle- } \\
\text { Moses }\end{array}$ & 2003 & $\begin{array}{l}\text { Deciduous } \\
\text { hardwoods }\end{array}$ & Ontario, Canada & $18.8 \%$ & Closed \\
\hline Link, et al. & 2004 & $\begin{array}{l}\text { Pseudotsuga } \\
\text { menziesii }\end{array}$ & $\begin{array}{l}\text { S. Washington, } \\
\text { USA }\end{array}$ & 22.8 and $25.0 \%$ & Closed \\
\hline Pypker, et al. & 2005 & $\begin{array}{l}\text { Pseudotsuga } \\
\text { menziesii }\end{array}$ & $\begin{array}{l}\text { S. Washington, } \\
\text { USA }\end{array}$ & $25 \%$ & Closed \\
\hline
\end{tabular}

Table 1. Leading Studies on Interception. These studies focused on either Douglas-fir forests, open-grown trees, or interception in general. * Rothacher found throughfall of $76 \%$ summer and $86 \%$ winter; I have converted to interception without factoring stemflow. 


\section{Closed-canopy v. open-grown}

Canopies of forests or plantations are more or less continuous from tree to tree. Indeed, branches of neighboring Sitka spruce (Picea sitchensis) frequently overlap (Ford and Deans 1978), although increasing age of the forest can lead to gaps where limbs or whole trees have fallen down (Gash et al. 1995, Link et al. 2004). Due to the close proximity of trees in forests, light intensity decreases from the top of the canopy, which can result in lower branches dying off and reducing a tree's total leaf area. These conditions lead to high, shallow canopies, and lower Leaf Area Indices (LAI) (Makela 1997). Furthermore, the tight-knit canopy of forests may prevent moist air from leaving shaded areas, thus reducing evaporation (Teklehaimanot et al. 1991). Anecdotally, a walk in the forests of the Pacific Northwest can show that the conditions underneath closed canopy are often more humid, with less airflow, than conditions outside the forest. In these conditions, the closed-canopy of mature Douglas-fir forests catches between 22 and $25 \%$ of spring, summer and winter rainfall (Link et al. 2004, Pypker et al. 2005).

For open-grown trees, the interceptions rates on a single 9-year-old, $8.5 \mathrm{~m}$-tall Bradford pear and a single 8-year-old, $5.6 \mathrm{~m}$-tall cork oak were 15 and 27\%, respectively (Xiao, 2000b). However, these trees were not coniferous, and may not be analogous to the conifers native to the Pacific Northwest. Furthermore, the sample size was small, with only one tree for each species. Therefore, comparison of opengrown and closed-canopy interception for Douglas-fir is warranted. 


\section{Storm gaps}

Storm gaps are the times between the end of one storm and the beginning of the next. During the course of a rain event, rain stoppage may allow the canopy to partially dry. However, in interception studies, it is useful to know when the canopy is completely dry and evaporation from wet leaves is complete (Gash 1979). The quantification of 'storm gap' depends on the study goals and is a key issue addressed in interception studies. For example, Rutter et al. (1971) sought a fine time-scale understanding of how and when interception occurred in canopy, and used five-minute intervals during rainy periods. In contrast, Gash (1979) tested a model which assumed a single storm per day, applying his model only to trees completely dry at storm's onset. In between, Mulder (1985) chose two-hour gaps while Link (2004) selected gaps of six hours. Ultimately, distinguishing the individual non-convective storms that dominate from November to March in the Pacific Northwest may not be possible without highly sophisticated methods (George Taylor, pers. comm.).

I used Link's six-hour gap because it allowed me to distinguish between rain events without having to bundle storms, for example, an early-morning storm and a late-afternoon storm, into a single rain event. On the other hand, a six-hour gap allowed a description of the Pacific Northwest's chronic, multi-day rainy periods, during which long periods of drizzle might not immediately register in a tippingbucket rain gauge, but would prevent measurable evaporation. 


\section{Tree morphology}

Scientists have studied interception on a myriad of tree species, from pines (Rutter et al. 1971, Gash 1979) to cork oak (Xiao et al. 2000b) to a suite of eastern North American hardwoods (Price and Carlyle-Moses 2003). The species of tree studied affects interception in three major respects: leaf fall dynamics, bark roughness, and tree architecture. Whether a species is deciduous or not affects its interception capacity. Trees that have lost their leaves have reduced surface area and support less water, reducing interception capacity. In the Pacific Northwest, most of a year's rain occurs in the months when deciduous trees are without foliage. In particular, Portland, Oregon's airport receives $67 \%$ (i.e. $61.5 \mathrm{~cm}$ of $92.2 \mathrm{~cm}$ ) of its average annual rainfall during the five months from November through March, during a period that deciduous trees typically have no leaves (National Weather Service 2011).

Bark roughness is another important factor in interception differences among tree species. Trees with smooth bark tend to have high rates of stemflow, or flow down branches or trunks. Horton (1919) found that, in the heaviest storms, $10 \%$ of the rain falling on beech (Fagus spp.) was stemflow, as compared to pine (Pinus spp.), for which stemflow leveled off at $2 \%$ for the same storms. High rates of stemflow mean rain is less likely to be held in cracks along stem and branch surfaces, giving the water less time to evaporate back into the atmosphere. Smooth bark allows water to quickly 
run off its surface, leading to larger collection volumes than expected for rough bark (Voigt 1961, Rothacher 1963).

Trees with rougher, craggier bark, on the other hand, can hold more water, creating another reservoir that intercepts rainfall. Several studies of Douglas-fir forest (Rothacher 1963, Link et al. 2004, Pypker et al. 2005), and of maritime pine (Pinus pinaster) (Lankreijer et al. 1993) indicated that stemflow constituted a minor, even negligible, destination of rainfall on rough-barked species.

Tree architecture describes how the parts of a tree are arranged. Within the field of interception studies, canopy is affected in at least three ways: abrasion, leaf layering and variability. Increased density increases abrasion, the process by which branches on neighboring trees break the others' branch tips. Higher density, or stocking rates, leads to greater degrees of self-pruning, and smaller, less filled-in canopies as a result (Takahashi 1996).

The way in which a species tends to layer its leaves, either predominantly monolayer or predominantly multilayer, also helps explain how canopies change from closed to open growth scenarios (Horn 1971). A tendency towards multiple layers may represent a species response to reduced moisture through smaller, widely-spaced leaves, or greater light availability. Both smaller leaves and greater light availability would be increasingly appropriate in open-grown trees.

Variability of canopy structures can occur in a number of ways, including branch angle (Horton 1919), petiole sturdiness (Liu 1997), maximum foliage height 
(Godfree 2000), live crown ratio (Godfree 2000), gap fraction (Gash et al. 1995), biomass and branch diameter (Ishii et al. 2000), needle age (Jensen and Long 1983) and specific leaf area (St. Clair 1994). These structures can vary among species (Horton 1919), and can vary within a species (Godfree 2000). The work done on specific leaf area, for example, describes leaf areas ranging from $60.9 \mathrm{~cm}^{2} / \mathrm{g}$ (St. Clair 1994) to $85.7 \mathrm{~cm}^{2} / \mathrm{g}$ (Del Rio and Berg 1979) per tree. The variability in specific leaf area would have obvious consequences for interception: the larger a tree's leaf area, the more rain it is likely to intercept. Variability has been observed as the source of important channeling effects and gaps, making large error estimates unavoidable (Ford and Deans 1978).

\section{Evaporation}

Interception is the evaporative process that occurs when water is resting on a plant. It is a purely physical process, unrelated to the physiology of the supporting organism. Evapotranspiration is the process by which the water at the top of a plant's water column is either used in photosynthesis or exits the leaves' pores as water vapor. The process of interception inhibits that of evapotranspiration. Once leaves are dry, stomata can begin releasing water vapor from within the plant. Until all the leaves are dry, the water remaining on the canopy surface is said to be stored. The length of time needed to completely dry, thus restoring a tree's full storage capacity, varies according to many of the environmental factors mentioned below. 
The physical basis of canopy evapotranspiration from vegetation canopies is frequently modeled by the Penman-Monteith equation (Dingman 2002):

$$
E=\frac{\Delta \cdot(K+L)+\rho_{a} \cdot c_{a} \cdot C_{a t} \cdot e_{a}^{*} \cdot\left(1-W_{a}\right)}{\rho_{w} \cdot \lambda_{v} \cdot\left[\Delta+\gamma \cdot\left(1+C_{a t} / C_{c a n}\right)\right]}
$$

which incorporates a wide range of environmental factors to estimate evapotranspiration for vegetation. The equation calculates evapotranspiration $[\mathrm{E}]$ by combining the short- and long-wave radiation multiplied by the slope of the curve of saturation-vapor vs. temperature $[\Delta \cdot(\mathrm{K}+\mathrm{L})]$ with an atmospheric term composed of current air density $\left[\rho_{a}\right]$, the specific heat of air $\left[c_{a}\right]$, and saturation vapor pressure $\left[e_{a}^{*}\right]$. The combination of energy and air capacity are then divided by a water term, composed of the current density of water $\left[\rho_{w}\right]$, the latent heat of vaporization of water $\left[\lambda_{v}\right]$, and, once again, the slope of the curve of saturation-vapor vs. temperature $[\Delta]$, the psychometric constant $[\gamma]$ and the fraction of atmospheric conductance for water vapor $\left[\mathrm{C}_{\mathrm{at}}\right]$ out of a canopy's conductance $\left[\mathrm{C}_{\mathrm{can}}\right]$. Rutter (1971) adjusted this equation to better account for evaporation from the uneven surface of tree canopy.

Gash's (1979) work incorporated models by Rutter et al. (1971) and PenmanMonteith (Dingman 2002), but proposed a model simplifying the data needs of earlier approaches. He described interception on the basis of daily rainfall, with the assumptions that rainfall and evaporation were consistent throughout the day's storms, and that water dripping from the canopy is nearly non-existent at the start of storms ("wetting up") and short-lived afterwards (Gash 1979). Gash's model is a 
simplification of Rutter et al. (1971), in that it describes interception only on the basis of daily rainfall, not as an up-to-the-minute total (Lloyd et al. 1988, Hormann et al. 1996). However, the assumptions used by Gash limit the usefulness of this model as a practical way to describe interception at a given site. Despite their shortcomings, physically-based models have proven adequate in various applications, and, more importantly, have framed the interception discussion by describing the key concepts of interception. Several of those concepts are central to the idea of an interception water balance.

Water Balance

Dating back to Horton (1919), but more explicitly starting with Helvey and Patric (1965), interception models use some variant of a water balance calculation:

$$
\mathrm{I}=\mathrm{R}-\mathrm{T}-\mathrm{Tr},
$$

where (I) is interception), (R) is incident rainfall, (T) is canopy throughfall, and (Tr) is stemflow. However, after a certain amount of rainfall, a tree's canopy reaches its storage capacity (S), and no longer intercepts rain. All rainfall after this time is assumed to be throughfall.

Some studies have tried to measure these fluxes directly. For example, Helvey and Patric (1965) compiled a number of interception datasets from throughout eastern North America and used linear regression models to estimate interception rates among them. That approach, though, was thought only applicable to eastern North American 
hardwood forests (Aston 1979). Rutter et al. (1971) found evaporation from pine forests to be many times that predicted by the Penman-Monteith equation (Dingman 2002). Thus, Rutter et al. (1971) combined Penman-Monteith with a rigorous, computerized approach to atmospheric measurements that formed the basis for many interception studies that have followed (e.g. Gash 1979, Lankreijer et al. 1993, Liu 1997). Teklehaimanot et al. (1991) suspended cut trees by cranes during wetting and measured the time at which their storage capacity leveled off. The effort required for such a technique is substantial, not to mention destructive.

Liu's model was instructive in that, unlike Rutter et al. (1971), it used no empirical parameters, relying on a canopy dryness index, rain intensity, and a time interval (Liu 1997). The data requirements for the Liu model include maximum canopy storage, the range of meteorological data required to assess evaporation rate, and both pre- and post-storm precipitation. While many studies have attempted to measure the inputs and outputs of a forest system necessary for modeling, this kind of rigor was beyond the scope of my study.

\section{Spacing}

Despite attempts to fine-tune models for the lattice of spaces in natural forest canopies referred to as "gap fraction" (Aston 1979, Gash et al. 1995), most studies have neglected the effects of wide spacing on interception; it remains a factor for which no model explicitly accounts. A study of specifically-spaced plantation trees 
correlated increased drying with increased spacing of trunks, as one might expect, although the mechanics of how this happens were not described (Teklehaimanot et al. 1991). Furthermore, their subject trees were grown in rows $2 \mathrm{~m}$ apart, so it is not clear to what extent these trees were truly open-grown. It seems likely that trees in the same row grew up with trees close by on two sides, although this was not specified.

Wind

While increased spacing improves airflow, and thus interception, wind can also decrease the amount of rain being held in storage. High winds can cause trees to sway, shaking water off their leaves, and converting potential interception to mere throughfall (Hormann et al. 1996). Wind also changes the angle of leaves, causing them to drain their stored water (Xiao et al. 2000a).

\section{Urban Hydrology}

The effect of trees on urban hydrology is just starting to be understood. Trees are not part of the standard city stormwater system of gutters, pipes and treatment plants. However, as ecologists expand their studies to include the built environment of cities and towns, the linkage between urban forest and urban hydrology becomes more important. 


\section{Urban forests}

The spacing of urban trees is markedly different from that of forest trees. Urban areas, almost by definition, tend to have very little remaining forest land, though some cities such as Portland, Oregon, have preserved sizable stands of mature forest within parks. In such environments, interception may reflect that of native forests.

City parks composed of mature stands, however, are relatively infrequent. Urban trees are more likely found in less arboreal parks, in private yards, and along streets; these trees can be described as open-grown, growing with wide gaps between individuals. A hike in any forested environment readily shows that open-grown trees are comparatively rare, suggesting different, and perhaps higher, rates of interception per tree in the overall urban forest, as compared to native forests.

\section{Urban Stormwater}

The hydrology of urban systems is also quite different from the hydrology of forested systems. Urban environments tend to have much more impervious surface, in the form of streets, parking lots, sidewalks and roofs: in Portland they cover at least $30 \%$ of 350 square kilometers. Impervious surfaces prevent infiltration of rainwater as well as directing it into stormdrains. These larger flows suspend more pollutants and 
transport them into waterways; their higher energy can also damage infrastructure, as well as natural channels (Walsh et al. 2005).

In some cities, stormwater and sewage are conveyed to treatment facilities in shared pipes. When large storms create volumes of water larger than can be treated, the excess water is shunted to nearby waterways, creating Combined Sewer Overflows (CSOs). Spills of untreated water can create additional costs in the form of fines or, in the case of Portland, significant lawsuits. The lawsuits filed by Northwest Environmental Advocates as a response to excessive CSOs have forced the City to increase stormwater storage and management capacity through pipe upgrades, construction of ecoroofs and bioswales, and increased tree-planting. Interception is seen as an integral part of mitigating stormwater (Environmental Services 2011), and many studies support the idea that vegetation, in general (Sanders 1986), and interception, in particular (McPherson et al. 1999, Xiao and McPherson 2003, McPherson et al. 2005), are critical in this role. At the same time, the general lack of intact, contiguous tree canopy in cities means fewer trees are available to mitigate stormwater. Filling gaps in the canopy by planting more trees, especially around impervious areas, would decrease stormwater runoff by increasing interception. A better understanding of interception would allow a better calculation of how many trees to add and at what spacing. 


\section{$\underline{\text { Reasons to Research Open-Grown Trees }}$}

The definition of open-grown trees is potentially broad, encompassing any tree able to grow a full canopy with maximum branching. In cities, branches are often pruned up a trunk for safety or access reasons, though the tree might still be considered open-grown. Another definition might include trees whose stems are far enough apart to allow full sun on the whole canopy. For my study, I considered trees with a gap around their perimeters at least as wide as the tree crown's perimeter to be open-grown.

My hypothesis that distance between trees increases interception is based on two observations. First, given a crown-width gap, an open-grown tree has much higher light availability. Increased light over the tree's lifetime typically leads a tree to retain branches much further down the trunk than trees with less light. My first observation, then, is that the fuller canopies of open-grown trees tend to have a larger leaf area and, thus, larger storage capacities. Larger storage means a greater volume of water can be held in place to evaporate, although this could also mean longer drying times with no net benefit. My second observation is that having sufficient space around the tree leads to an increased ability to dry the canopy. Open-grown trees have better airflows, drying more quickly and allowing a shorter "recharge" time (Teklehaimanot et al. 1991). 


\section{Research Questions and Hypotheses}

In this thesis, I hypothesized that Douglas-fir trees (Pseudotsuga menziesii) standing apart from other trees ('open-grown') intercept a larger volume of water than Douglas-fir trees standing near other trees ('closed-canopy'). To test my hypothesis, I have measured throughfall and incident rainfall to determine interception, and compared:

a) open-grown interception to published interception rates in forests;

b) open-grown interception to in situ closed-canopy interception. 


\section{Methods}

Overview

My overall approach was to capture rain dripping through the canopy of four open-grown and two closed-canopy Douglas-fir trees at Hoyt Arboretum, Portland, Oregon, from early November 2007 through March 2008. I measured throughfall in six fixed buckets per tree, at a frequency of every 1-3 days, depending on rain conditions. During the same time, I collected unobstructed rainfall at two "open-field" buckets, identical to those under the trees. Over the same period, I also took weekly readings from a nearby tipping-bucket raingauge in the Hoyt Arboretum Visitor's Center maintenance yard. This raingauge, along with the open-field buckets and a tipping-bucket raingauge near the Children's Museum that was operated by the City of Portland's HYDRA network (site \#192), provided an estimate of the local incident rainfall. The difference between the throughfall and incident rainfall provided an interception value of the subject trees.

\section{$\underline{\text { Site }}$}

I chose Hoyt Arboretum, in the West Hills of Portland, Oregon, as my study site. The Arboretum features a wide range of trees, but was created in 1929 as a preserve for genetic specimens of soft-wood species, and particularly Douglas-fir. As a result, a large number of mature Douglas-fir trees occur mostly in small patches of forest, and occasionally as individuals. The Arboretum is $2.5 \mathrm{~km}$ west of the center of 
Portland $\left[45.52^{\circ} \mathrm{N}, 122.73^{\circ} \mathrm{W}\right]$, making it a convenient study location. The West Hills (elevation: $244 \mathrm{~m}$ ) tend to get more rain than the official weather station at Portland International Airport [elevation: $61 \mathrm{~m} ; 45.53^{\circ} \mathrm{N}, 122.67^{\circ} \mathrm{W}$ ] (Johnson 1987). The study sites all occupied the south-facing slopes of the Arboretum (Figure 1), along regularlymaintained trails and close to two tipping-bucket raingauges. 


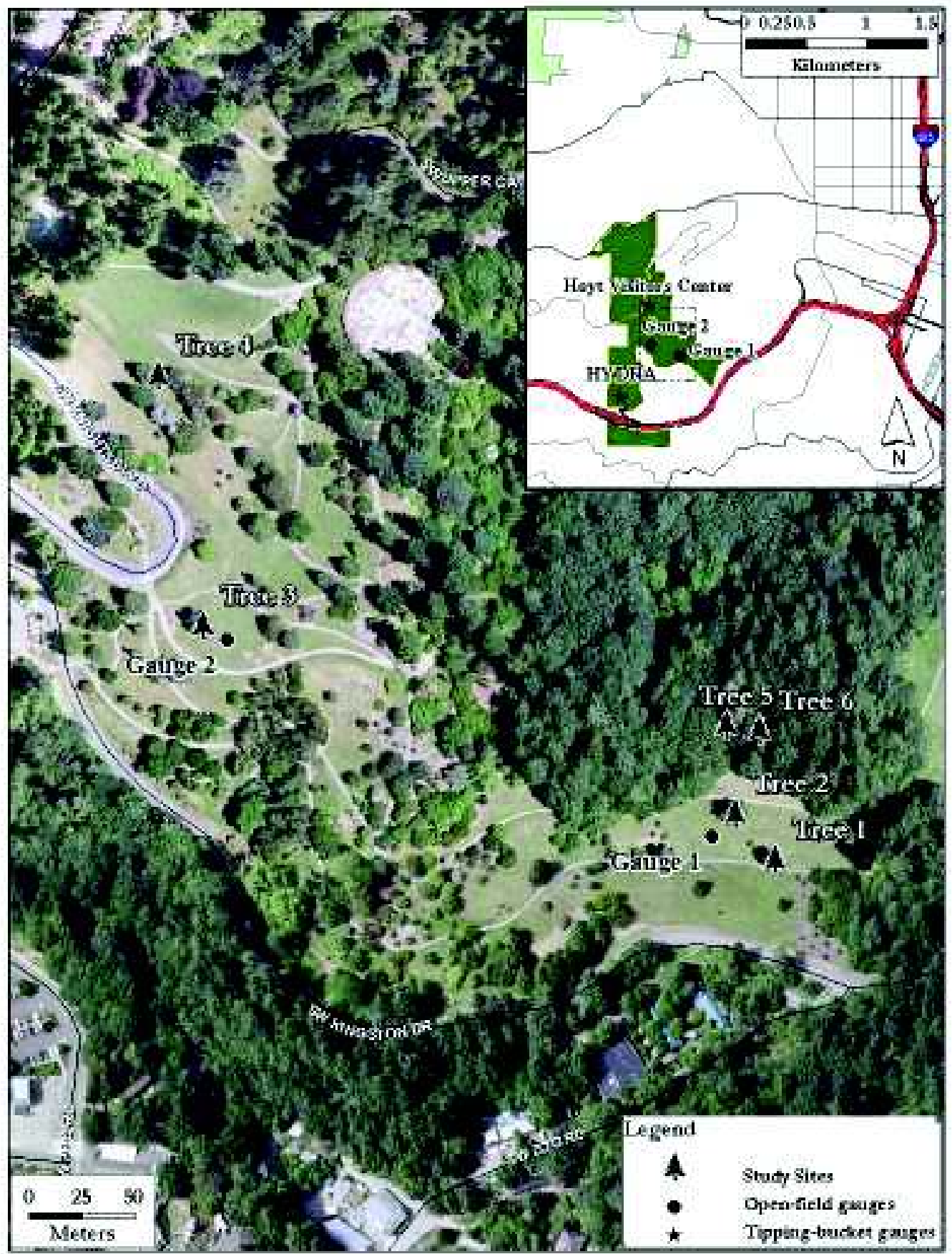

Figure 1. Map of Study Sites and Raingauges at Hoyt Arboretum in Portland, Oregon. Trees 1-4 are open-grown while trees 5-6 are closed canopy. Hoyt Arboretum is $2.5 \mathrm{~km}$ west of downtown Portland. All four gauges ( 2 tipping-bucket and 2 open-field) are shown in the inset map. 
$\underline{\text { Trees }}$

I selected Douglas-fir trees as the single species of study primarily because it is the dominant local conifer. Furthermore, in situations where increased urban interception is desired (for stormwater mitigation, for example), the ability of Douglas-fir trees to catch water during winter's high-rain season make this species an obvious candidate. The height and aspect were determined by clinometer, diameter at breast height (DBH) was measured by logging tape, and elevation was noted from a GIS contour layer. Projected crown area was estimated at the time of bucket placement; the method for finding estimated leaf area is described later in this section. The findings of these measurements are presented in Table 2.

\section{Open-grown}

I selected four Douglas-fir trees as my open-grown study subjects \#1-4 (Figure 2). All trees had a DBH of at least $40 \mathrm{~cm}$, and an estimated height of at least $11 \mathrm{~m}$ (Table 2). All would have been considered mature (Figure 2), and were probably at least 30 years old, although I did not core them. Tree 4 was part of the Arboretum collection; records indicate it was planted in 1980, though the age at planting is not

known. All trees were on south to southwest aspects, at elevations between $221 \mathrm{~m}$ and $242 \mathrm{~m}$. All trees also had branches to within $3 \mathrm{~m}$ of the ground, with branches present along more than three-quarters of their height. Three trees had no other trees or structures within at least a full-canopy-width around their perimeter. Tree 4 was 
neighbored by one full-grown tree to the southeast, with touching canopy edges, and another to the northeast, with canopy edges about $7 \mathrm{~m}$ apart. Tree 4 had full canopy on all sides, indicating little or no growth interference by either neighbor. Despite the relative abundance of open-grown Douglas-fir trees at the Arboretum, most had had enough lower limbs missing to disqualify them from the study. Tree 4 was included, then, despite neighboring trees, because of its full vertical canopy.

Trees 1 and 2 were located within 50m of each other, between the Maple and Hawthorne Trails at Hoyt Arboretum, at elevations of 236m and 241m and on the same, due-south-facing aspect (Figure 1). Open-field collection bucket \#1 stood in their vicinity, at least $10 \mathrm{~m}$ distant from any obstruction. Tree 3 stood about $500 \mathrm{~m}$ to the west of trees 1 and 2, near a hairpin bend in Knights Road, at an elevation of $255 \mathrm{~m}$ and on a slope with an aspect of 253 degrees. Open-field collection bucket \#2 was about $15 \mathrm{~m}$ east of tree 3 . Tree 4 stood about $120 \mathrm{~m}$ north-northwest of tree 3 , along the Holly Trail, at an elevation of $258 \mathrm{~m}$, and on a slope with an aspect of 219 degrees (Figure 1). 

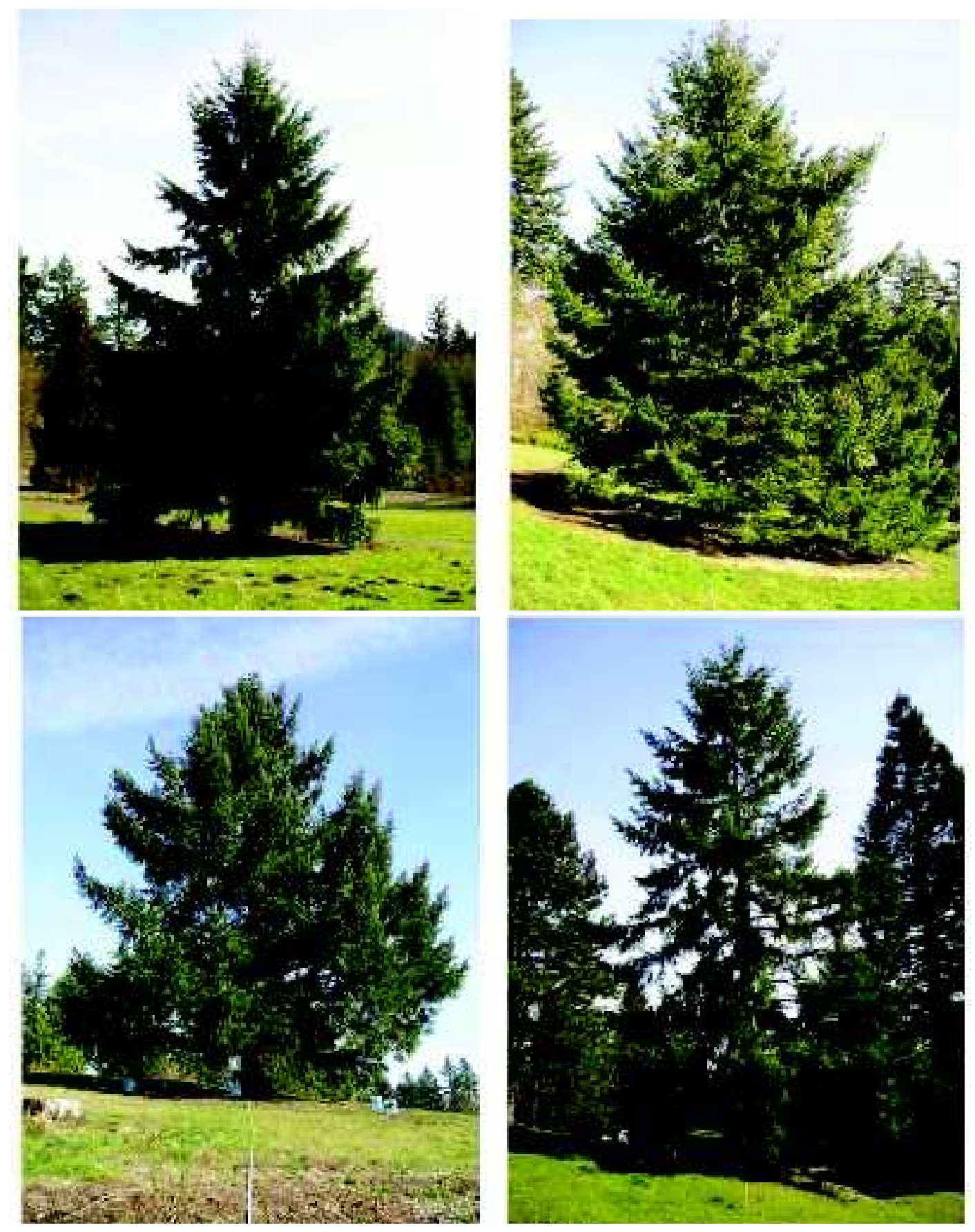

Figure 2: Photos of Open-grown Douglas-firs. Study trees 1 [upper left], 2 [upper right], 3 [lower left] and 4 [lower right]. 


\section{Closed-canopy}

I selected two trees, \#5 and 6, from within a forested stand just uphill from the Hawthorne Trail and tree 2 (Figure 3). The edge of the stand was $20 \mathrm{~m}$ from trees 1 and 2, although trees 5 and 6 were another $35 \mathrm{~m}$ into the patch, and $5 \mathrm{~m}$ higher in elevation. Trees 5 and 6 had a similar girth (at least $40 \mathrm{~cm}$ ) to the open-grown trees, although they were at least twice as tall. These trees were surrounded $(>90 \%)$ by other trees of similar height, and their branches began at least $15 \mathrm{~m}$ up the trunk.

\begin{tabular}{|c|c|c|c|c|c|c|}
\hline & $\underline{\text { Tree } 1}$ & $\underline{\text { Tree } 2}$ & $\underline{\text { Tree } 3}$ & $\underline{\text { Tree } 4}$ & $\underline{\text { Tree } 5}$ & $\underline{\text { Tree } 6}$ \\
\hline Height (m) & 11.3 & 15.0 & 15.3 & 13.4 & 44.6 & 41.0 \\
\hline Diameter Breast Height $(\mathrm{cm})$ & 43 & 48 & 51 & 45 & 81 & 70 \\
\hline Aspect & 181 & 181 & 253 & 219 & 175 & 175 \\
\hline Projected Crown Area $\left(\mathrm{m}^{2}\right)$ & 63.9 & 111.5 & 66.2 & 55.2 & 42.4 & 34.4 \\
\hline Leaf Area $\left(\mathrm{m}^{2}\right)$ & 66.1 & 93.0 & 70.9 & 69.5 & $\mathrm{n} / \mathrm{a}$ & $\mathrm{n} / \mathrm{a}$ \\
\hline Elevation at base (m) & 236 & 241 & 255 & 258 & 246 & 246 \\
\hline Canopy Type & open & open & open & open & closed & closed \\
\hline
\end{tabular}

Table 2. Characteristics of Study Trees. The table summarizes some of the key physical characteristics of all six trees studied. 


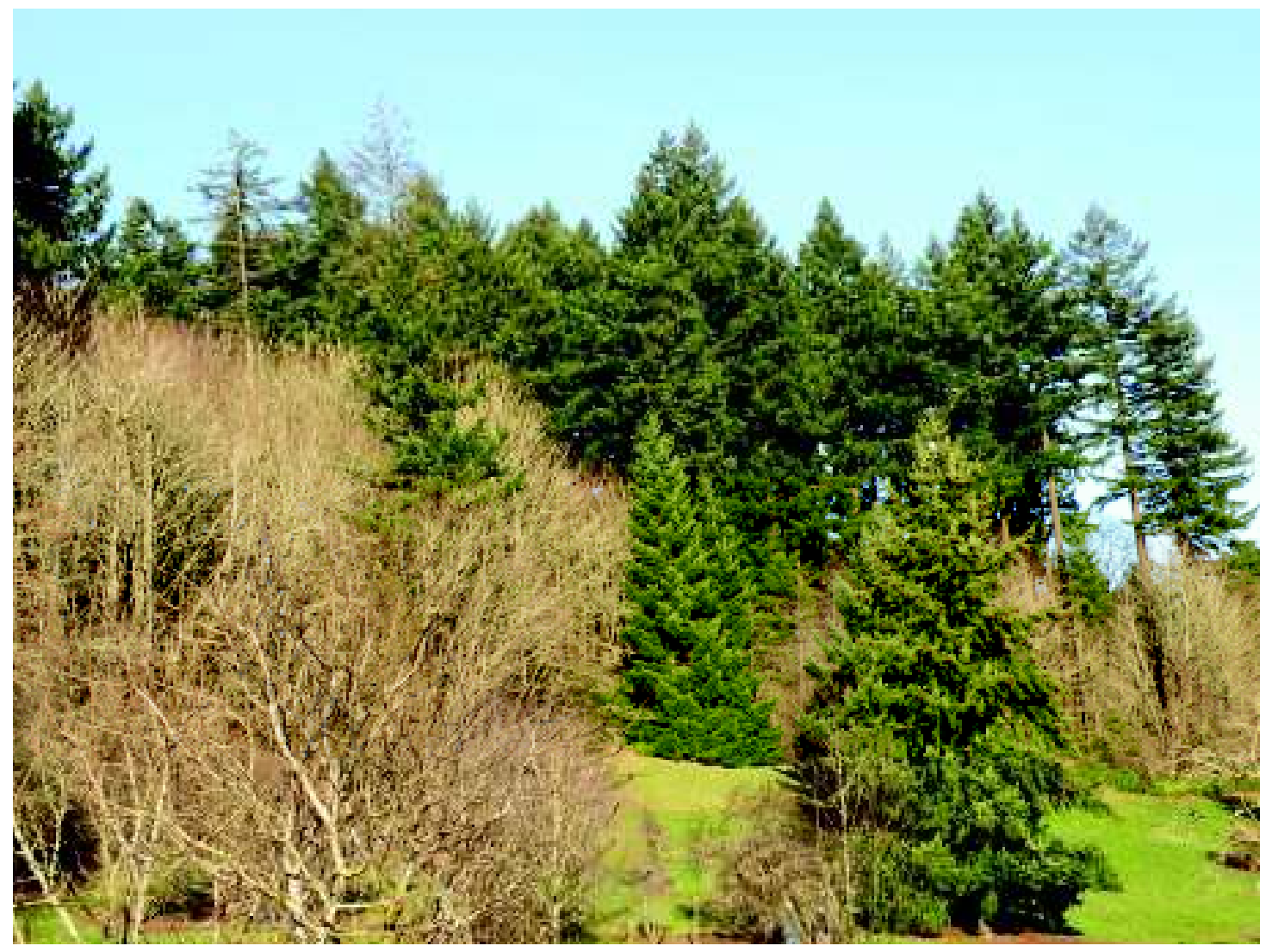

Figure 3. Photo of Closed-canopy Douglas-fir Stand. Trees 5 and 6 stood in the center of the stand in the distance, about $35 \mathrm{~m}$ uphill from the clearing edge.

\section{Collecting throughfall}

Buckets v. troughs

Most interception studies have used either buckets or troughs to collect throughfall. The buckets are cylinders of various sizes topped with funnels (Gash 1979), while troughs are shaped like, and often made of, ordinary rain gutters (Rutter et al. 1971). It has been argued that troughs, because they capture both high-drip and low-drip areas under canopy, better reflect the variability of a tree's throughfall 
(Kostelnik et al. 1989). The steep sides of the funneled tops of buckets, however, are thought to reduce splash; the relatively shallow angle at which troughs are placed encourages loss of throughfall via splashing (Puckett 1991). Direct comparison of the two methods found no statistical difference between bucket catch and trough catch, for either Sitka spruce (Picea sitchensis) or Japanese larch (Larix kaempferi) (Reynolds and Neal 1991).

A study of throughfall variability under a Western redcedar (Thuja plicata) and Western hemlock (Tsuga heterophylla) forest demonstrated the relationship between variability and the number of bucket collectors (Kimmins 1973). The study, which used 94 collectors, found that rainfall totals of less than $6.0 \mathrm{~cm}$ per week had increasing variance, requiring more buckets to reduce variation (i.e. within $10 \%$ standard deviation). Given the increasingly large number of buckets required to maintain small standard deviations, the author recommended stopping at 30 collectors and accepting larger (20\%) standard deviations (Kimmins 1973).

From a practical standpoint, buckets were much simpler and much less costly to use than troughs. Troughs required many pieces to prevent evaporation loss and to accurately convey rainfall to storage. They also required careful calibration to determine their catchment area. Finally, they were relatively delicate and unstable; it took little interference to render a trough unusable. In contrast, buckets were cheap, easily installed, presented minimal evaporation and had no additional parts. Damaged buckets were quickly replaced. Given that recent studies have used arrays of up to 24 
tipping-bucket raingauges and up to 48 manual raingauges to assess throughfall (Link et al. 2004, Pypker et al. 2005), the use of buckets for my study seemed appropriate.

\section{Number of buckets}

To determine how many buckets should be placed per tree, I ran a pilot test in the spring of 2007, placing 14 buckets under a Douglas-fir for several rain events. Most storms were too small for the canopy saturation that leads to throughfall, but two storms provided at least $2.5 \mathrm{~cm}$ of throughfall. I randomly sampled from the throughfall totals of a given number of the 14 buckets. Using a Monte Carlo analysis written in R, a statistical software, I randomly sampled and averaged each of the given number 50 times for a progression of sample sizes, starting with 1-bucket samples and ending with a 14-bucket sample (and the actual sample mean). A variogram suggested that the range of covariance dropped into a more consistent range at about six buckets (Figure 4). 


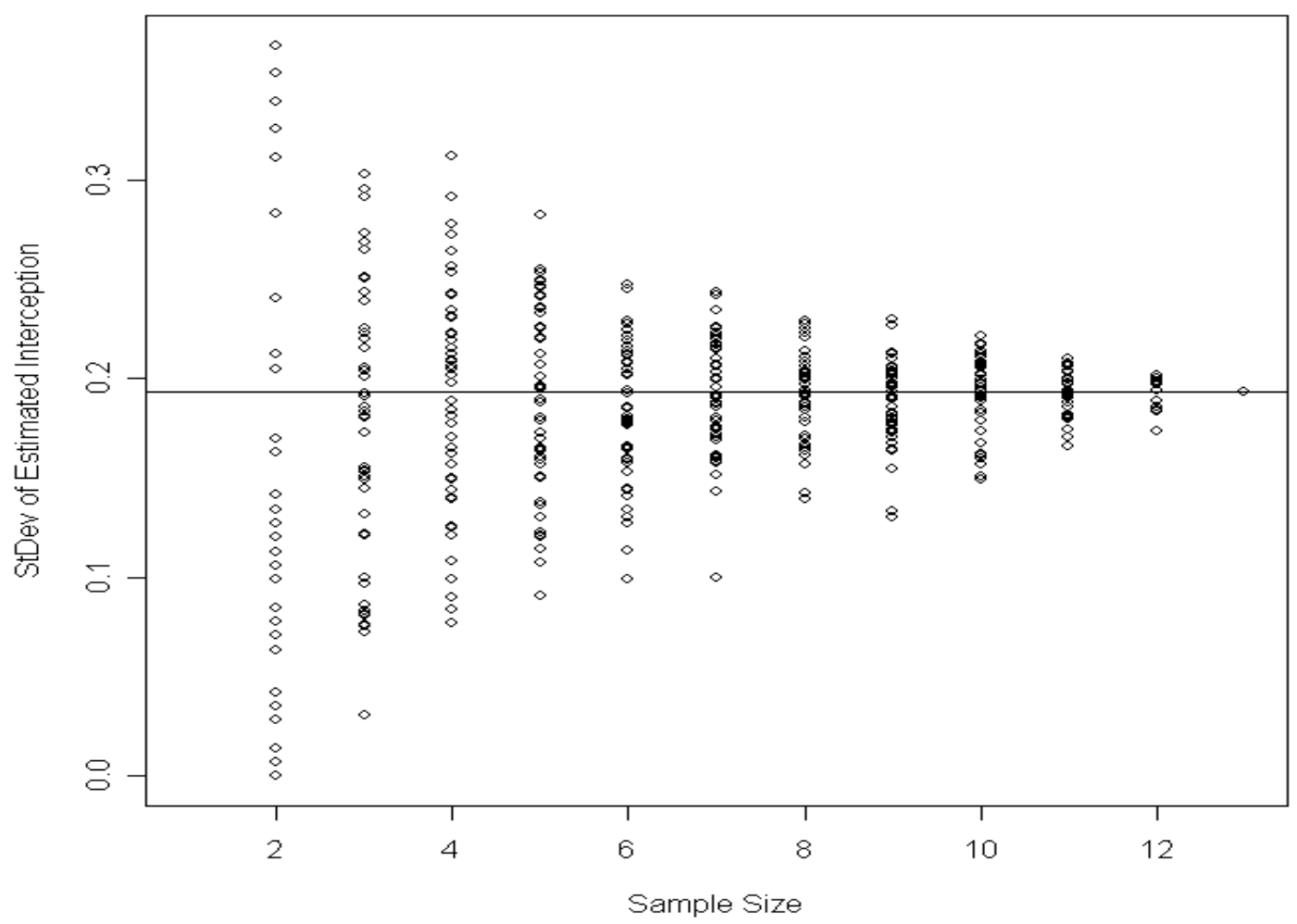

Figure 4. Variogram of May 2007 Storms. The variogram shows decreasing variability of measured throughfall with an increasing number of collectors. The $\mathrm{x}-$ axis is the sample size of the collectors, while the y-axis shows the standard deviation of the estimated interception.

The throughfall data from those two storms supported two conclusions. First, six was an adequate number of buckets for capturing the variability of throughfall for this particular tree. Second, the data showed that the south side of the tree had more throughfall. For my target tree in May, the south side allowed more rain to come through, suggesting the importance of storm direction. Given that the angle of incidence might differ from storm to storm, as well as from tree to tree, a truly random 
placement of buckets might put my buckets largely out of the key sector for that storm at that tree. For this reason, I used a stratified approach, dividing the crown area into three equal wedges. Within each 120-degree-wedge, two buckets were placed randomly.

\section{Construction}

Given limitations in funding and concerns about vandalism, I attempted an approach that did not use large numbers of tipping-bucket rain gauges, instead modifying 5-gallon polycarbonate water cooler bottles ("buckets"). I cut the top off each bottle about $17 \mathrm{~cm}$ below the end of the spout, and flipped it, creating a tightfitting funnel (Figure 5). I recorded the width of the newly formed opening and numbered each bucket. I tried several methods for keeping the buckets in place under the trees. The cheapest, most reliable method was duct-taping a $5 \mathrm{~cm}$ section of $1.1 \mathrm{~cm}$ (0.5in)-diameter PVC pipe to the side of each bucket, using the PVC pipe as a sleeve around a $0.7 \mathrm{~m}$ section of rebar staked in the ground (Figure 6). I gave most of the buckets a slug of cement ballast. As the undersides of the bottles resemble the bottoms of wine-bottles, I poured Portland cement into the dimple and then epoxied the slug into place once it had dried. This ballast proved unnecessary, since the PVC sleeve/rebar combination was sufficient support, and the epoxy holding the cement failed on many buckets after 8-10 weeks. 


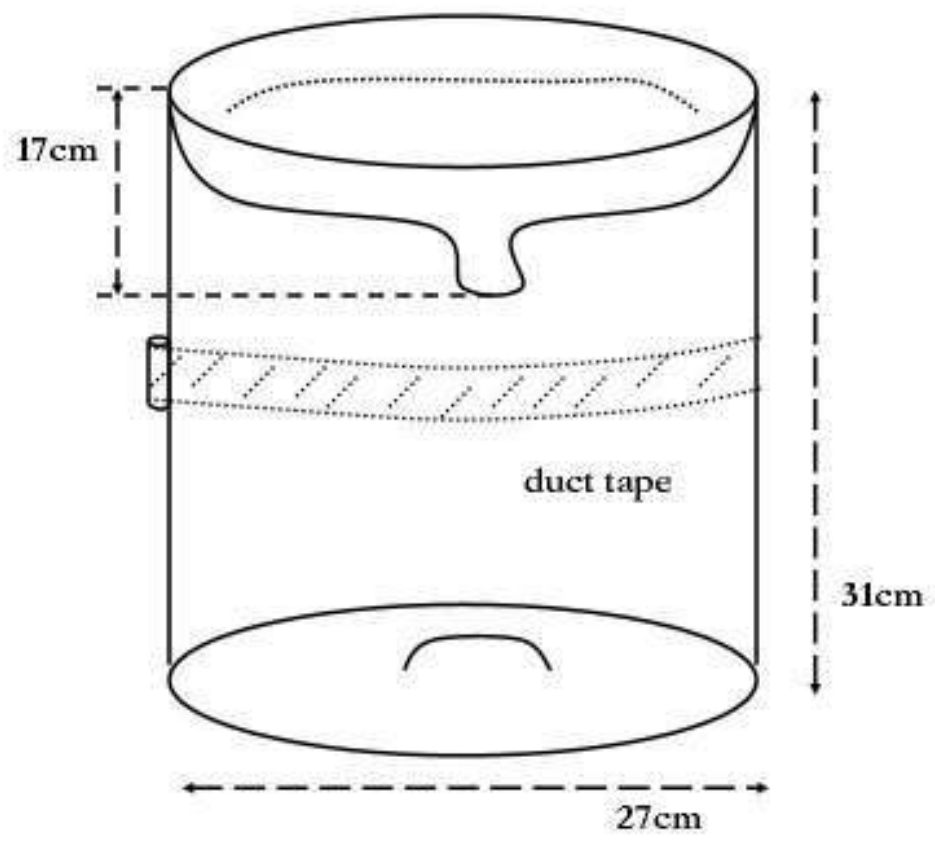

Figure 5. Schematic of a Sample Collection Bucket. The spout of a 5-gallon water cooler bottle is cut off and flipped over to act as a funnel, while a short section of ducttaped PVC pipe holds the bucket onto a rebar stake.

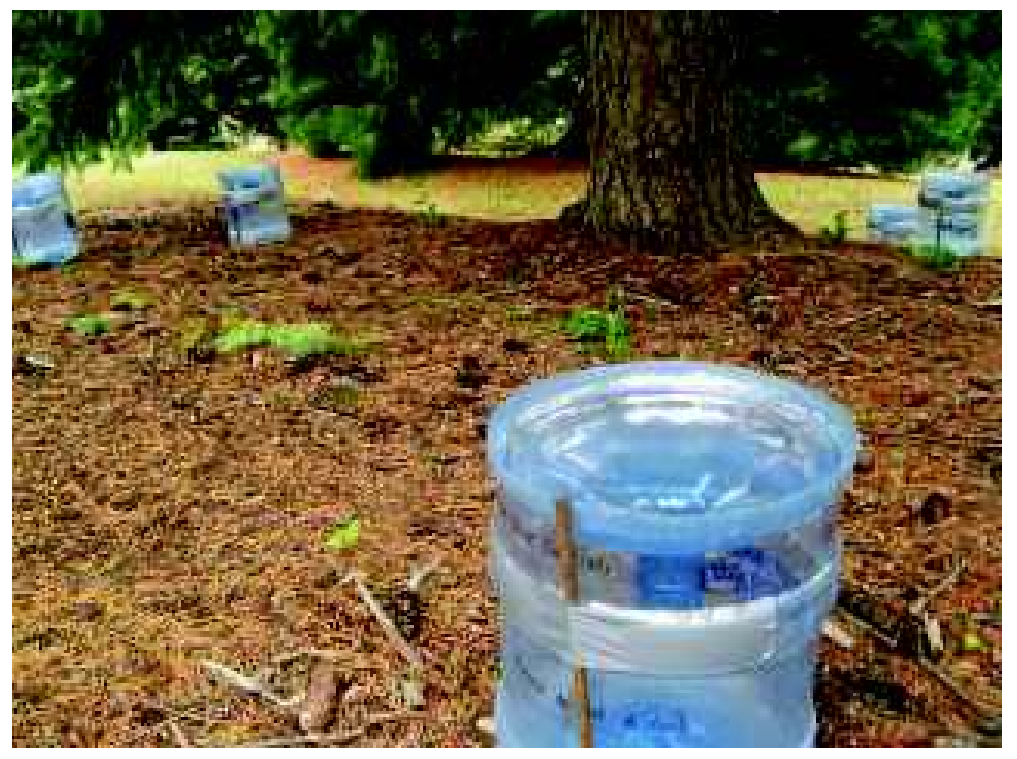

Figure 6. Photo of Buckets at Study Tree 4. The photo shows bucket placement and attachment to rebar stakes. 


\section{Placement}

The location of each of the six buckets per tree was partly randomized. For each $120^{\circ}$ wedge, starting at 0 -degrees north, I randomly picked a bearing between 0 and 120 degrees. At that bearing, I measured the radius from the trunk surface to a point where the number of branches breaking a vertical line extending up from the tape went from three to two. This measurement was intended to make a somewhat conservative estimate of the canopy area, so as not to have buckets near the canopy edge. I then calculated the square root of a randomly-generated decimal to determine the bucket's placement in centimeters along the randomly-generated bearing (Figures 7-12). This procedure effectively randomized location over a circular area, although it was somewhat biased towards the interior. 


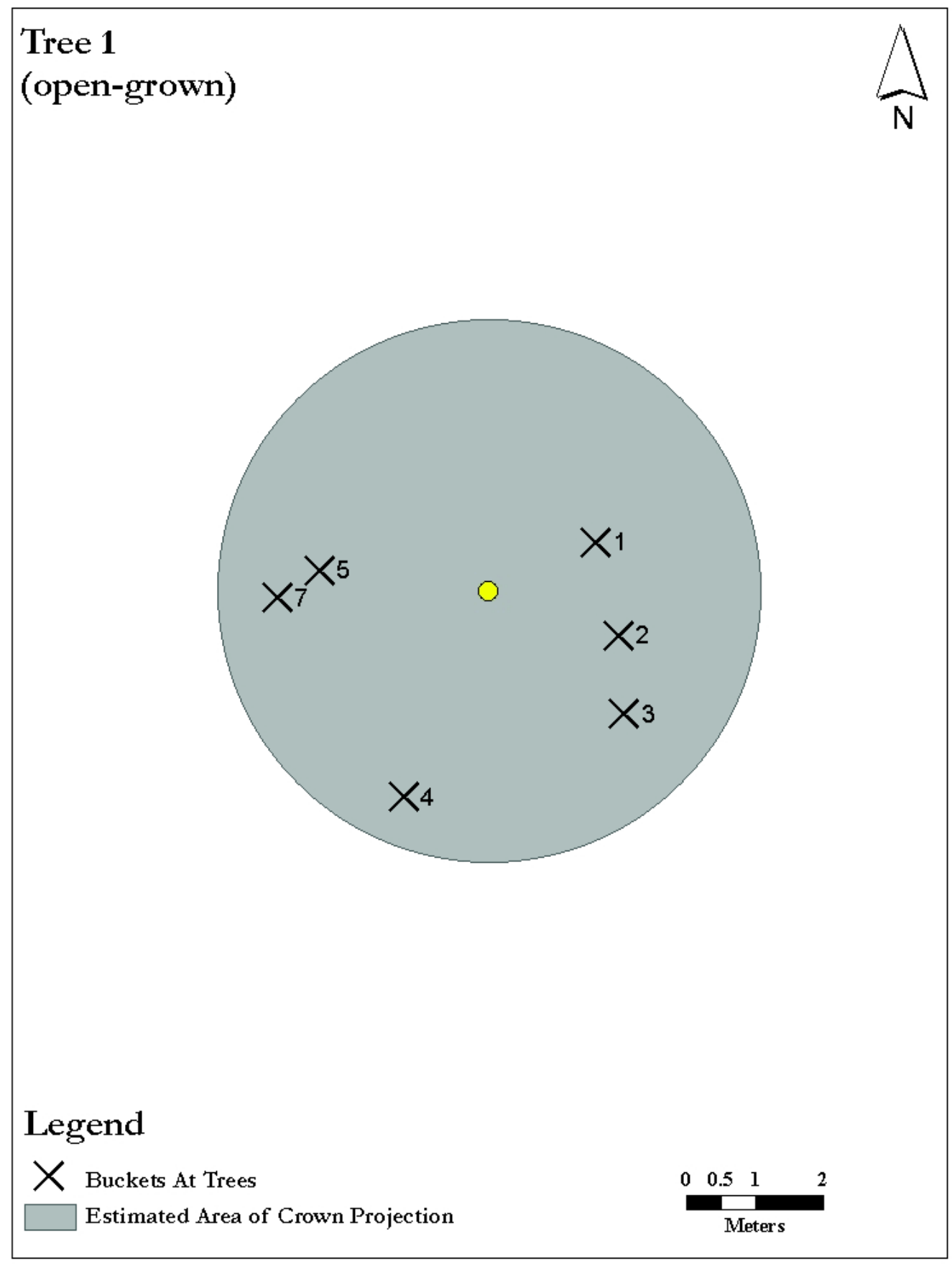

Figure 7. Bucket Placement at Study Tree 1. Tree 1 was open-grown, 20m south of tree 2, and near open-field raingauge \#2. It grew just south of the forested area where trees $5 \& 6$ grew. The approximate radius of the projected crown area is $4.0 \mathrm{~m}$. 


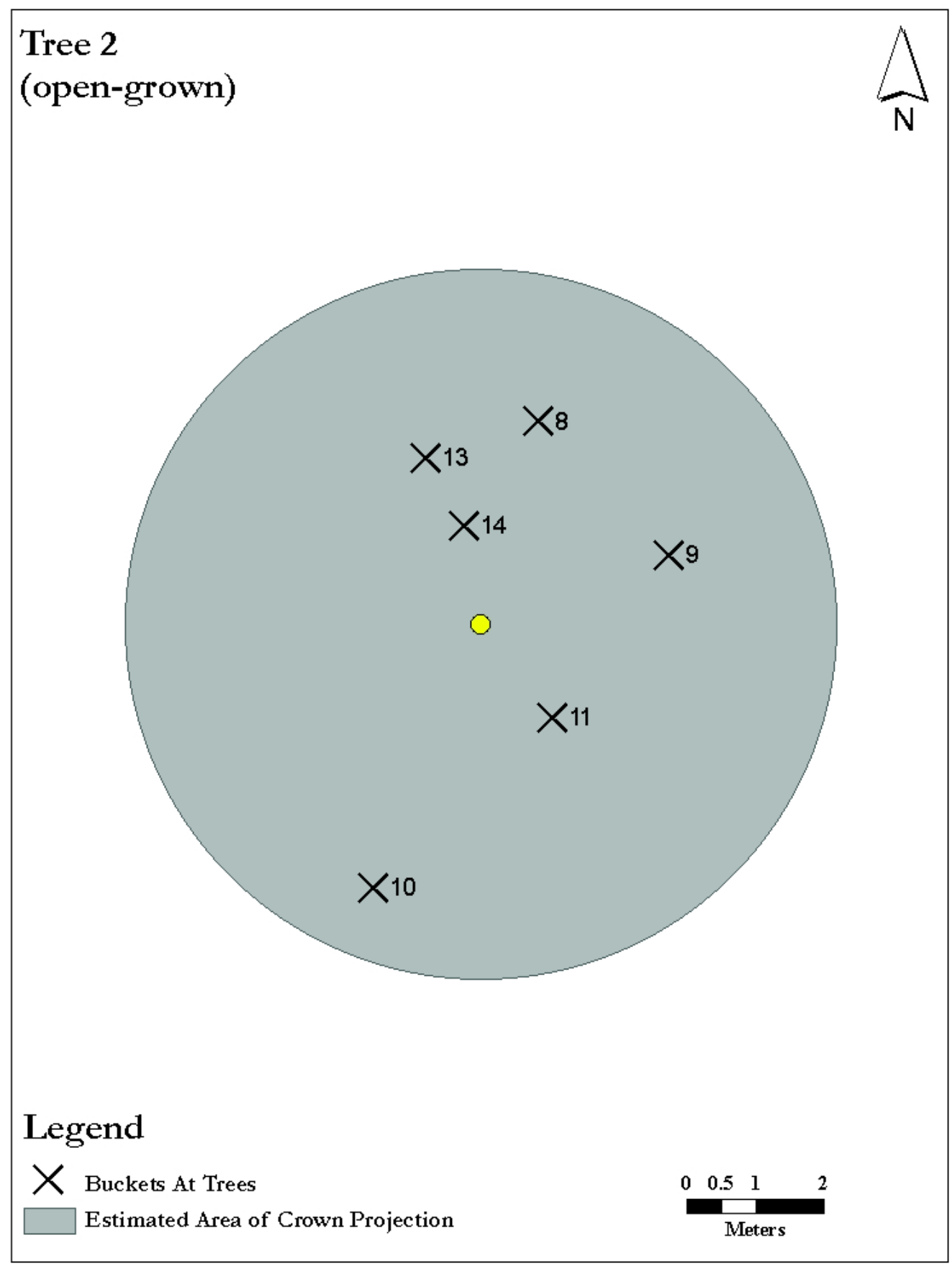

Figure 8. Bucket Placement at Study Tree 2. Tree 2 was open-grown, 20m north of tree 1, and near open-field raingauge \#2. It grew just south of the forested area where trees $5 \& 6$ grew. The approximate radius of the projected crown area is $5.3 \mathrm{~m}$. 


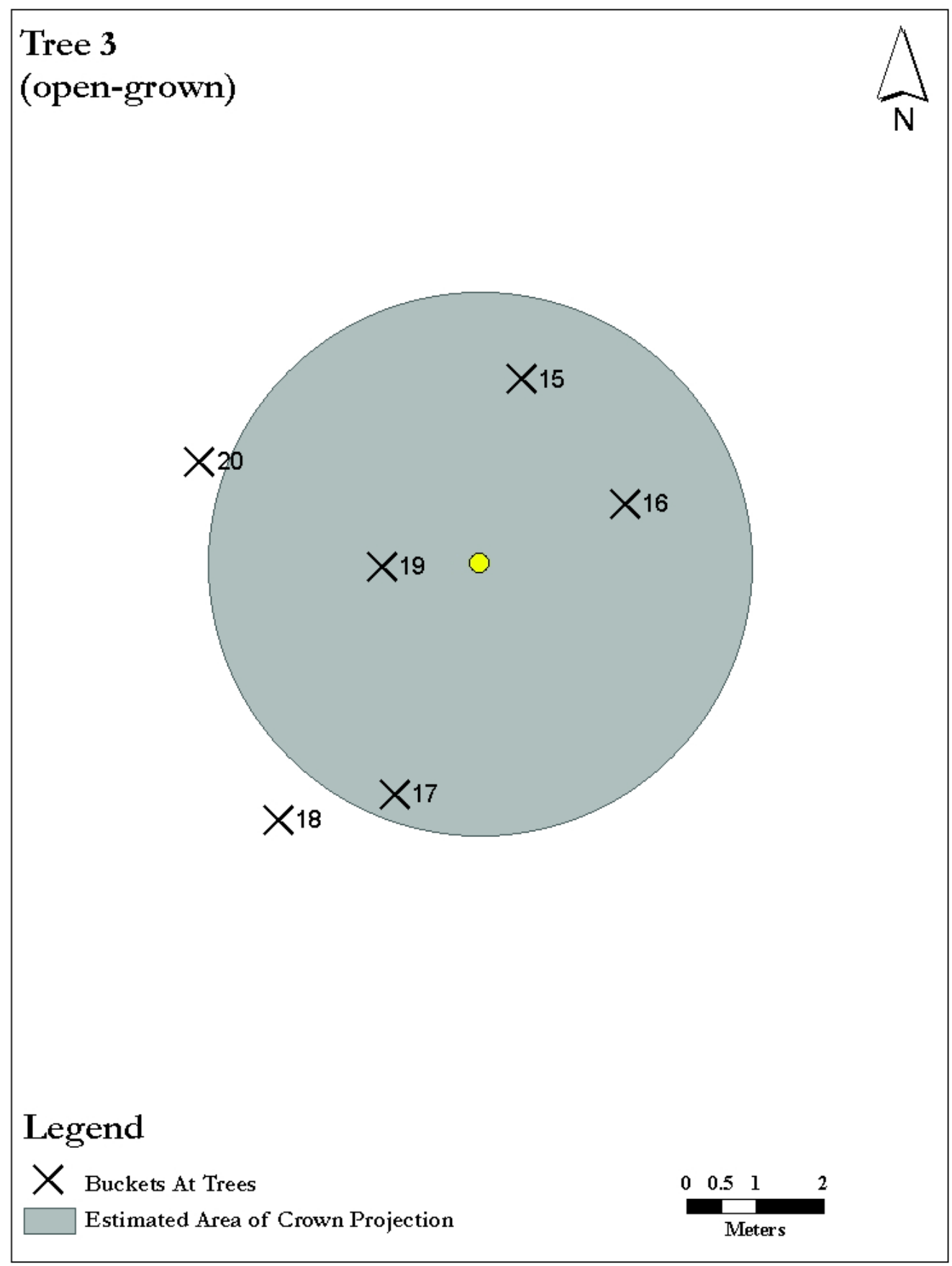

Figure 9. Bucket Placement at Study Tree 3. Tree 3 was open-grown, at the bend in Knights Road, and near open-field raingauge \#1. The approximate radius of the projected crown area is $4.1 \mathrm{~m}$. 


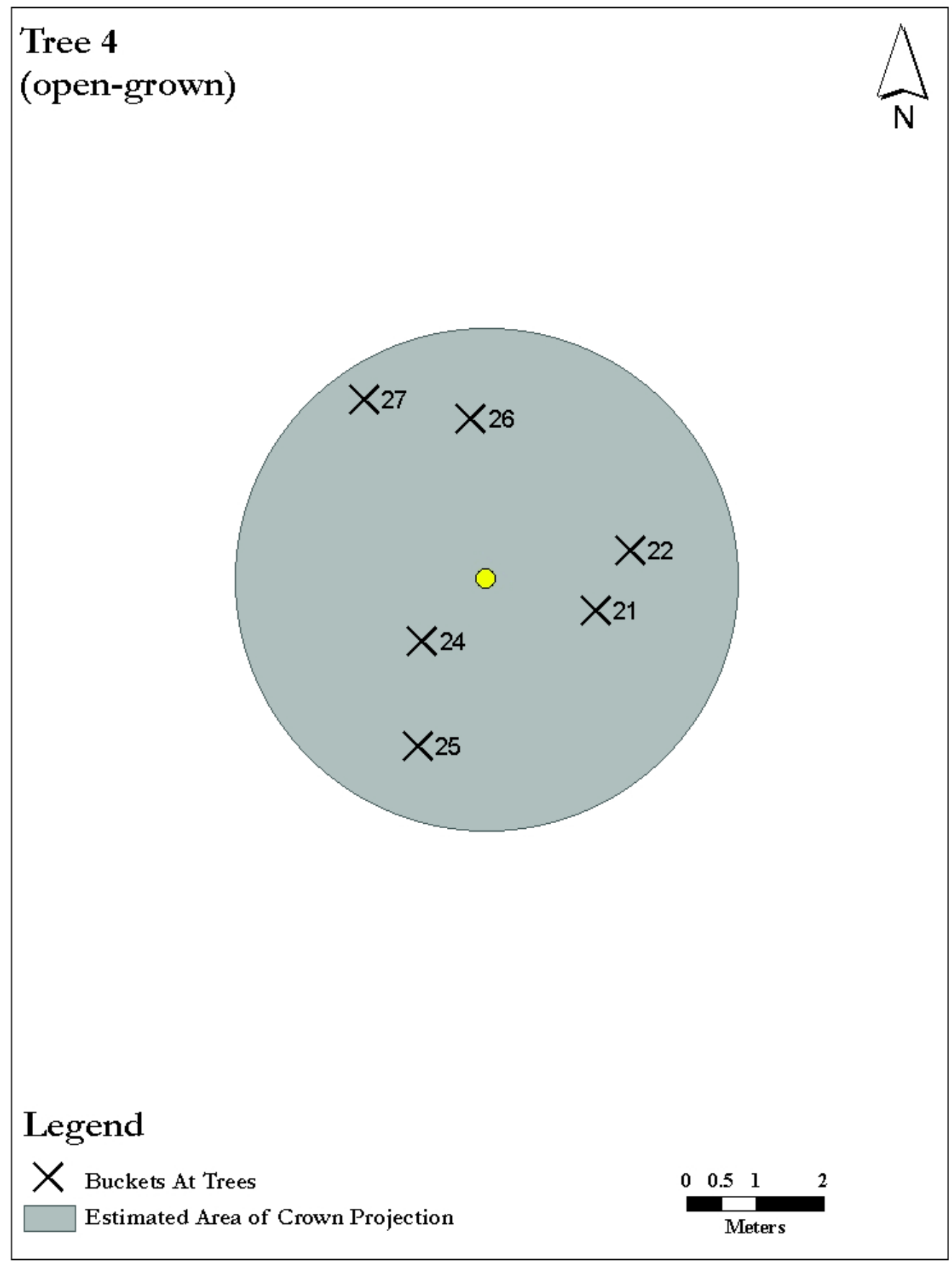

Figure 10. Bucket Placement at Study Tree 4. Tree 4 was open-grown, north of Knights Road, and about 200m from open-field raingauge \#1. The approximate radius of the projected crown area is $3.7 \mathrm{~m}$. 


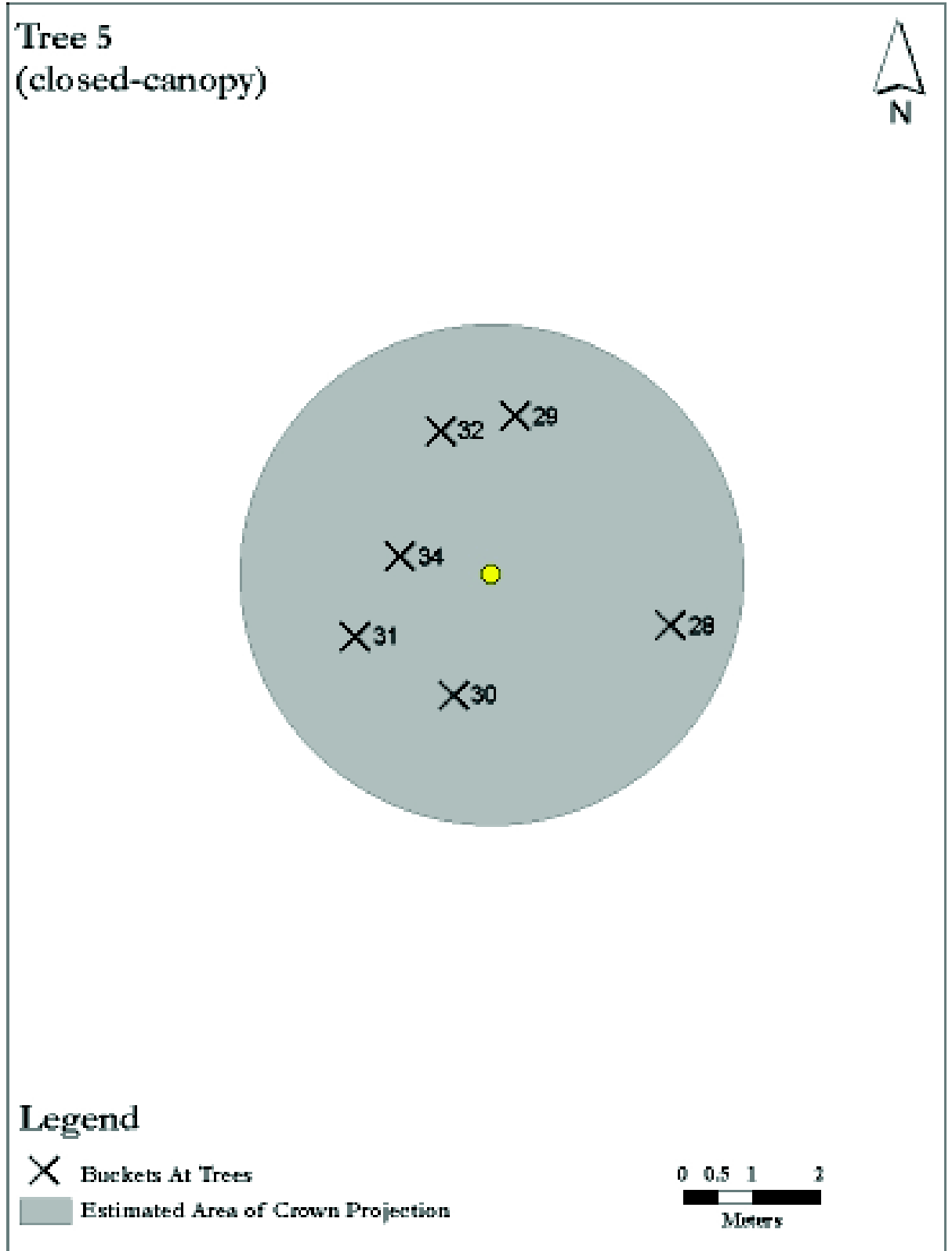

Figure 11. Bucket Placement at Study Tree 5. Tree 5 was a closed-canopy tree, growing in a stand of primarily Douglas-firs north of the clearing where trees $1 \& 2$ grew. Tree 6 was $5 \mathrm{~m}$ west. The approximate radius of the projected crown area is $3.7 \mathrm{~m}$. 


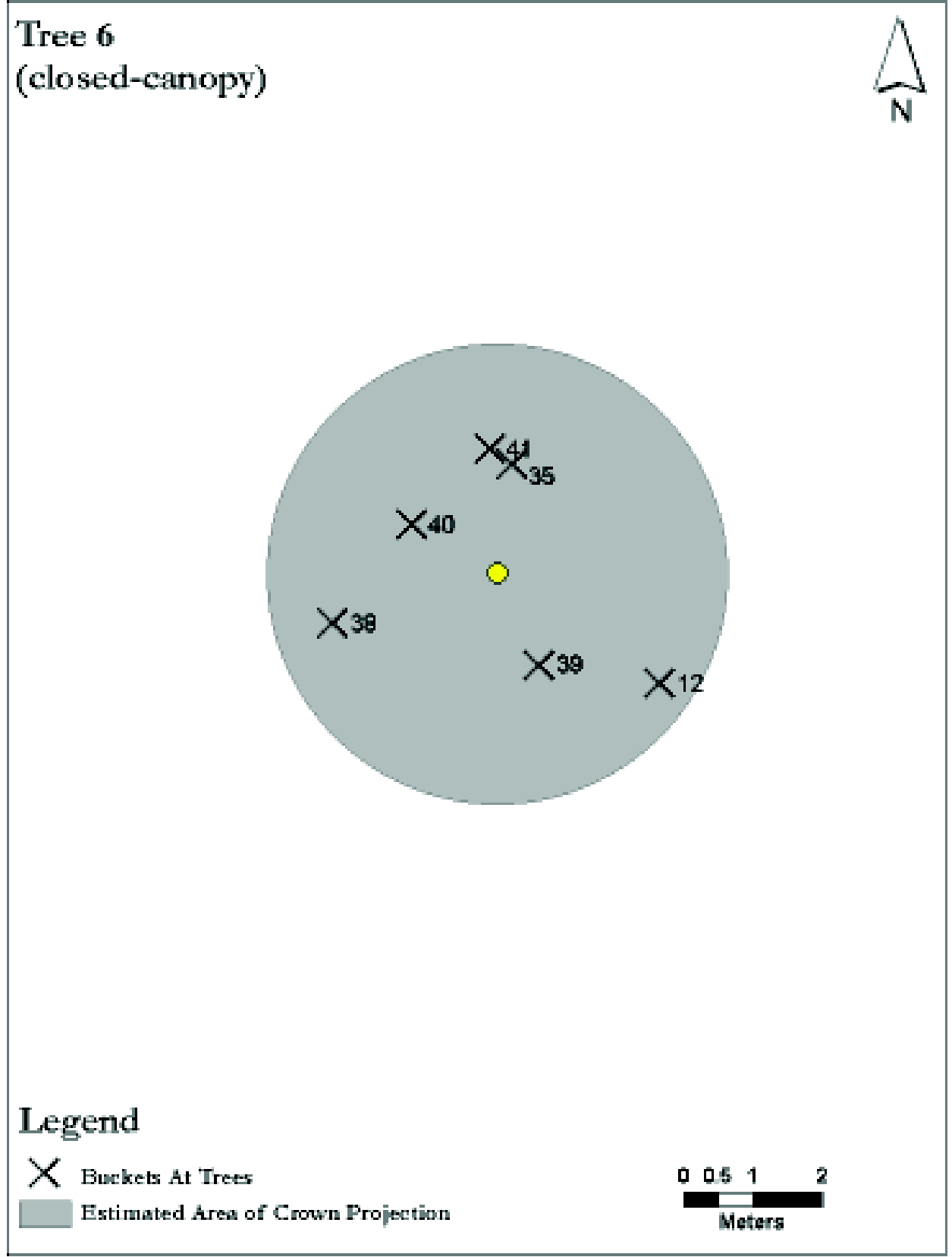

Figure 12. Bucket Placement at Study Tree 6. Tree 6 was a closed-canopy tree, growing in a stand of primarily Douglas-firs north of the clearing where trees $1 \& 2$ grew. Tree 5 was $5 \mathrm{~m}$ east. The approximate radius of the projected crown area is $3.3 \mathrm{~m}$. 


\section{$\underline{\text { Trunkflow }}$}

A study of the Wind River Canopy Crane Research Facility (2005) found that trunkflow for Douglas-fir does not typically contribute significant volumes to total throughfall. Previous work also indicated that trunkflow for Douglas-fir (Rothacher 1963), as well as other coniferous species (Mulder 1985, Lankreijer et al. 1993), is minimal. The roughness of Douglas-fir bark, and that of many mature conifers, prevents channeling and provides additional water storage in all but the heaviest storm events. Based on these studies, I did not collect trunkflow in this study.

\section{$\underline{\text { Leaf area }}$}

I used a method for determining leaf area based on Peper and McPherson (2003). I took color digital photos of each tree from two angles approximately perpendicular to each other and at a distance of $18 \mathrm{~m}$ from estimated trunk centers. A white board of known dimensions was also photographed at a distance of $18 \mathrm{~m}$. Two

pictures of each tree, as well as one of the white board, were reduced to monochromes in PhotoShop, and the pixels of each were counted. For each tree, the number of pixels from the two profiles that were perpendicular were averaged, and the average count divided by the number of pixels on the white board to get a canopy area estimate. Leaf area estimates using this method approximate leaf area as measured by comprehensive, fully-destructive means (Peper and McPherson 2003). Leaf area 
estimates of the open-grown study trees are included among the trees' characteristics (Table 1). Directly photographing the closed-canopy trees was not practical.

\section{Collection}

Sample collections were made daily during rainy periods, with each collection period as short as possible. Usually a collection took about 45 minutes to complete for all trees, though for the sake of differentiating events, each sample collection is considered a moment in time. Attempts were made to collect during periods of no rainfall, in hope of bracketing a storm between collections, although this was not always successful. I collected water from buckets by pouring into either a $100 \mathrm{~mL}$ or a $1000 \mathrm{~mL}$ graduated cylinder, as conditions warranted. Ultimately, this led to a precision of $10 \mathrm{~mL}$, since I used the $1000 \mathrm{~mL}$ cylinder for most collections. Time of 'first bucket emptied' was recorded for every tree, and the time of the first bucket emptied at the first tree was used for all trees during that collection. This convention allowed for clearer comparison with the Hoyt weather station data. The water volume in each bucket was divided by its measured aperture area (in $\mathrm{cm}$ ) to give a linear rainfall depth for that bucket during that collection period. Linear depths were compared to incident rainfall depths and the difference was calculated as the interception for that bucket for that collection. I averaged all bucket interception values to arrive at a mean interception value for that tree over the given storm event. Study period interception averages are discussed in the next section. 
Interception calculation

Calculations were based on the water balance equation already described (equation 2) as: $\mathrm{I}=\mathrm{R}$ - T - Tr. Rainfall totals (R) were taken from open-field collectors set up near the study trees; tipping-bucket gauges at each tree were not costeffective when compared to the potential risk of vandalism. Trunkflow (Tr) was assumed to be zero, as described above. Throughfall (T) was calculated from the bucket collectors by dividing the collected water volume by the area of each bucket's opening, giving a depth. For each collection, these depths were averaged at each tree. The mean of those averages gave a tree's interception over the study period. The difference between the nearest open-field bucket $(\mathrm{R})$ and the throughfall recorded under the study trees $(\mathrm{T})$ was restated as a percentage of $\mathrm{R}$, thus providing interception (I). To calculate study period interception, I summed the average depths of all collections for a given tree, then compared to the sum of all incident depths for the same period. This approach minimized rounding error. A representative sample of data follows (Figure 13); results will be shown later, and the complete dataset is available in Appendix A. 


\begin{tabular}{llrrrrr} 
& & $\underline{60}$ & $\underline{61}$ & $\underline{62}$ & $\underline{63}$ & $\underline{64}$ \\
Tree 1 & bucket 1 & 0.009 & 0.983 & 0.073 & 0.107 & 0.902 \\
& bucket 2 & 0.035 & 1.329 & 0.114 & 0.158 & 0.951 \\
& bucket 3 & 0.170 & 0.947 & 0.109 & & \\
bucket 4 & 0.115 & 2.182 & 0.245 & 0.293 & 1.490 \\
& bucket 5 & 0.043 & 1.422 & 0.127 & 0.165 & 0.711 \\
& bucket 7 & 0.041 & 1.671 & 0.130 & 0.179 & 0.911 \\
\hline \multirow{5}{\text{Tree2}}{} & mean (cm) & 0.069 & 1.422 & 0.133 & 0.180 & 0.993 \\
& & & & & & \\
bucket 8 & 0.021 & 1.340 & 0.120 & 0.179 & 0.902 \\
bucket 9 & 0.007 & 1.030 & 0.079 & 0.114 & 0.968 \\
& bucket 10 & 0.194 & 1.819 & 0.289 & 0.475 & 1.864 \\
bucket 11 & 0.059 & 1.787 & 0.143 & 0.214 & 1.170 \\
& bucket 13 & 0.032 & 1.446 & 0.082 & 0.133 & 0.656 \\
bucket 14 & 0.067 & 1.444 & 0.144 & 0.202 & 0.810 \\
\hline OF Gauge 1 & & & & & & \\
\hline
\end{tabular}

Figure 13. A Sample of Throughfall Data. The figure shows five collections (\#6064) for trees 1 and 2 as an example of collected data; values are given as depths in centimeters, and averaged at the bottom of each collection for each tree. The nearest open-field gauge recorded incident rainfall for the same period.

\section{$\underline{\text { Full-season interception analysis }}$}

The beginning of the study had several candidate 'start dates.' I was first able to collect from the open-grown buckets on 90ct2007, which is referred to as collection \#1. All subsequent collections proceed in order; the collection number is useful when referring to the data. Calibration and testing of the Hoyt Arboretum weather station (see 'Local weather data' for details) were completed on 180ct2007 [collection 5]. The open-field gauges were finally ready on 25Oct2007, and the next rain occurred on 
10Nov2007 [collection 10]. I put the closed-canopy sites out on 12 Nov2007, getting first results on 16 Nov2007 [collection 12]. Collection 12 is the first one that provided data from both open-grown and closed-canopy sites, while having local incident rainfall from the open-field gauges. Collections that contained more than two irregularities (buckets with no water) in either the open-grown or the closed-canopy group were removed from analysis. Of the 64 collections, 43 had sufficient data by these standards and comprised the final datasheet.

\section{$\underline{\text { Storms }}$}

I further analyzed individual rain events, or 'storms,' which I defined as a period of continuous or discontinuous hourly rainfall in which no rain-free gaps of more than 5 hours occurred. Gaps of 6 hours or more were assumed to indicate two different 'storms' (Link et al. 2004). The Hoyt Arboretum raingauge provided the hourly rainfall totals for determining gaps within/between storms. By this definition, I selected collections or combinations of collections in which the only rain in the bucket would be rain from a single, continuous period of rain. The first active day for all six buckets was 12 Nov2007, while 30Mar2008 was the last active day. I captured data on 76 total storms between those dates, isolating sixteen for analysis. 
$\underline{\text { Weather }}$

Low Temperatures

On 20Jan2008, I discovered fractures in several buckets. All cracks occurred in the plastic forming the bottom dimples of buckets. The fractures were likely a result of interaction between frozen water on the inner surface of the dimple and very cold concrete bonded to the outer surface of the plastic. The cracks resulted in lower collection volumes, which would in turn led to artificially high interception rates. It was important to know how far back the cracking occurred to correctly interpret the data already collected. Examining average hourly temperature data (Hoyt gauge) starting in October, there were a few nights of freezing and slightly-below-freezing $\left(0^{\circ}\right.$ to $-1.5^{\circ} \mathrm{C}$ ) temperatures between 23 Nov2007 and 26Nov2007. No sub-freezing period lasted for more than 11 hours. An 11-hour period of below-freezing temperatures also occurred the night of 9Dec2007. That stretch also included a three hour period of somewhat-colder-than-freezing temperatures $\left(-1.5^{\circ}\right.$ to $\left.-3.0^{\circ} \mathrm{C}\right)$. Several periods of slightly below-freezing temperatures followed into the New Year.

The first night of not only extended sub-freezing temperatures but also colder temperatures was 15Jan2008. Average temperatures were freezing and belowfreezing for 18 hours, including 9 hours of somewhat-colder-than-freezing $\left(-1.5^{\circ}\right.$ to $\left.-3.0^{\circ} \mathrm{C}\right)$ temperatures. Because of the additional duration and the deeper cold, this night was a likely period to create and widen cracks to the point of leaking. 
After discovering fractures on 20Jan2008, I recorded colder temperatures from the night of $21 \mathrm{Jan} 2008$ to the night of $24 \mathrm{Jan} 2008$ with periods of sub-freezing temperatures for up to 20 hours per day, with well below-freezing $\left(<-3.0^{\circ} \mathrm{C}\right)$ temperatures for 7-11 hours each night. It seemed more likely that many of the cracks occurred during this time, though the water in buckets at that time was limited. All buckets were removed from the field on 28Jan2008 and leaks were tested on all buckets with fractures from $3 \mathrm{pm}$ on $28 \mathrm{Jan} 2008$ to $4 \mathrm{pm}$ on $30 \mathrm{Jan} 2008$. I added $1000 \mathrm{~mL}$ of water to each bucket, and set them in an outdoor, covered area in the Arboretum maintenance yard. The weather station recorded a 17-hour period of slightly below-freezing temperature during that time. Of the 38 buckets deployed, 12 leaked, and were replaced. Also, I have removed data from all buckets for the period 7pm on $15 \mathrm{Jan} 2008$ to $3 \mathrm{pm} 28 \mathrm{Jan} 2008$ [collections 41, 42 \& 43], prior to replacing visibly fractured buckets because too few intact buckets remained to give a consistent picture of the data.

\section{Local weather data}

The Hoyt Arboretum weather station was about 250 meters from the study sites. The raingauge [Onset's S-RGA-M0002], wind direction sensor, wind speed sensor, and temperature/relative humidity sensor were all linked to the data logger [Onset's HOBO Micro Station H21-002]. Incident rainfall, wind speed, wind gusts, temperature, and relative humidity were recorded in 1-minute increments; these data 
were downloaded after every collection to a laptop using Boxcar software. I placed two additional buckets in the open near Trees 2 and 3. To avoid rain shadow, both stood apart from all trees by at least the height of the neighboring trees. Minute-byminute weather data from the Arboretum were aggregated into hourly totals of rainfall, and hourly averages of wind speed, wind gusts, temperature and relative humidity. Down the hill about 300m and near the Childrens' Museum, the City of Portland operated a tipping bucket raingauge as part of its HYDRA network (Figure 1); the gauge has been recording data since at least March, 2005.

\section{Citywide weather data}

I compared the storm data collected in the fall and winter of 2007-08 with long-term data to obtain a better sense of what to expect for regional rainfall patterns. Long-term data for Hoyt Arboretum were not available; however, the Portland International Airport had rainfall records from 1Jan1950 to 31Dec2005. Assuming a 6-hour gap minimum between storms (discussed above) and that 'missing/trace' data could all be interpreted as 'no rainfall,' I analyzed the hourly rainfall data available from the National Weather Service. A script written for the statistical software, R, was used to determine the average length and intensity of storms over the 55-year period. I also analyzed these characteristics for the hourly data from both the airport and the Hoyt Arboretum weather station over my study period. I divided storm intensity into four categories based on rain intensity in the tipping bucket raingauge: 
low $(<0.25 \mathrm{~mm} / \mathrm{hr})$, medium $(0.25-0.75 \mathrm{~mm} / \mathrm{hr})$, high $(0.75-1.25 \mathrm{~mm} / \mathrm{hr})$, and very high $(>1.25 \mathrm{~mm} / \mathrm{hr})$. Both the historical data and the 2007-2008 field data were divided into these categories and compiled as shown in Figure 14. The filled-in bars represent historical data, while the striped bars represent airport data from 2007-2008. 


\section{Results}

Citywide weather data

Data from Portland International Airport showed that, on average, nearly 90 storms, as defined by the six-hour gap, occurred there per year. On the left hand side of the Figure 14, the lowest-intensity storms at Portland International Airport were nearly twice as numerous during the study year than during an average year, while other categories were more within expected ranges.

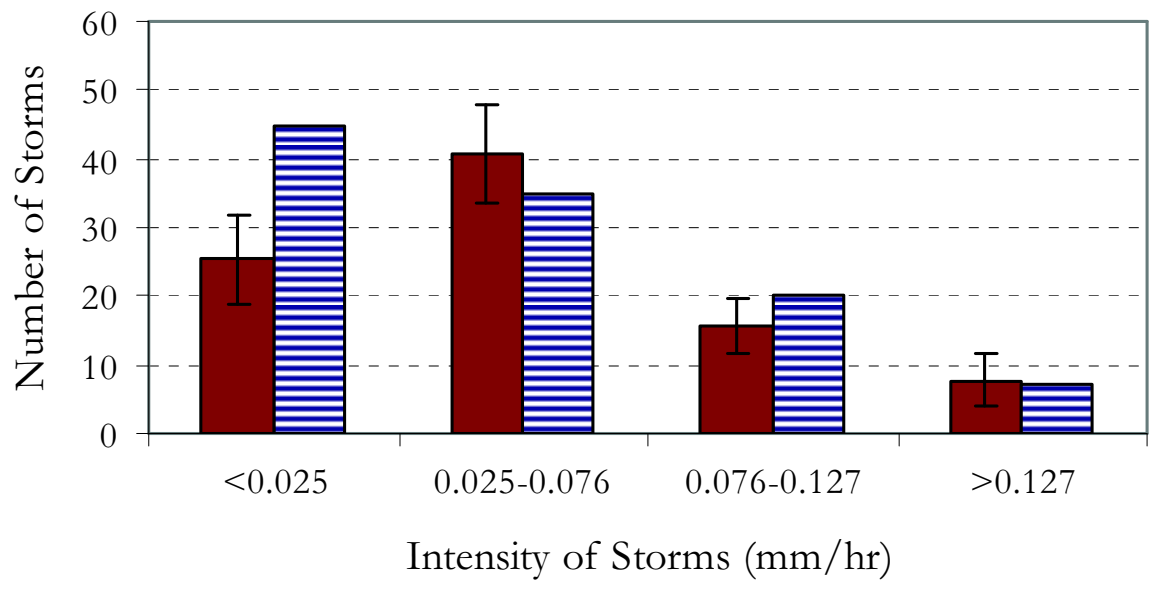

Figure 14. Comparison of Historic Storm Intensity. The 55-year average storm intensity from Portland International Airport from 1950 to 2005 [solid], as compared to that of the study period from 2007 to 2008 [lined]. Error bars show standard deviations for 55-year means.

\section{$\underline{\text { Isolated storms }}$}

Intensity of the sixteen isolated storms ranged from $0.17 \mathrm{~mm} / \mathrm{hr}$ to $2.02 \mathrm{~mm} / \mathrm{hr}$. The most intense storm was also the longest storm at 64 hours, though duration and intensity do not appear to correspond (Figure 15). Many of the higher intensity 
storms, with values above $1.0 \mathrm{~mm} / \mathrm{hr}$, were comparatively short, with durations of 14 , 18 , and 21 hours; conversely, one very long storm (58 hours) had a relatively low intensity of $0.46 \mathrm{~mm} / \mathrm{hr}$. Duration did not appear to affect interception (Figure 15).

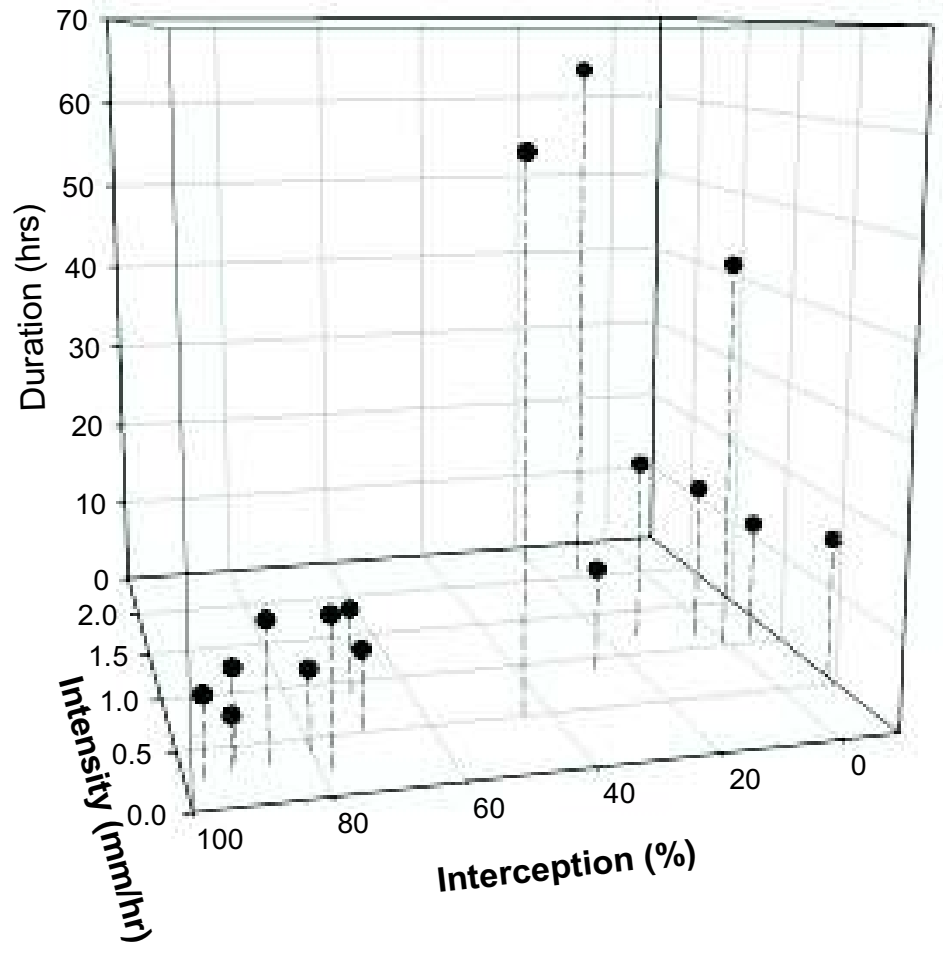

Figure 15. Sixteen Isolated Storms Compared by Intensity, Duration and Interception. Interception decreases from left to right while intensity $(\mathrm{mm} / \mathrm{hr})$ increases from front to back.

The prevailing wind direction for all sixteen storms, as tracked by the weather station at Hoyt Arboretum, was southerly (Figure 16). Hourly averages were compiled from minute-by-minute data taken for the duration of each storm; most storm tracks clustered around 180 degrees. Interception was not related to wind direction. Additional comparisons between interception and wind speed (Figure 17), and between interception and relative humidity (Figure 18) did not show relationships. 


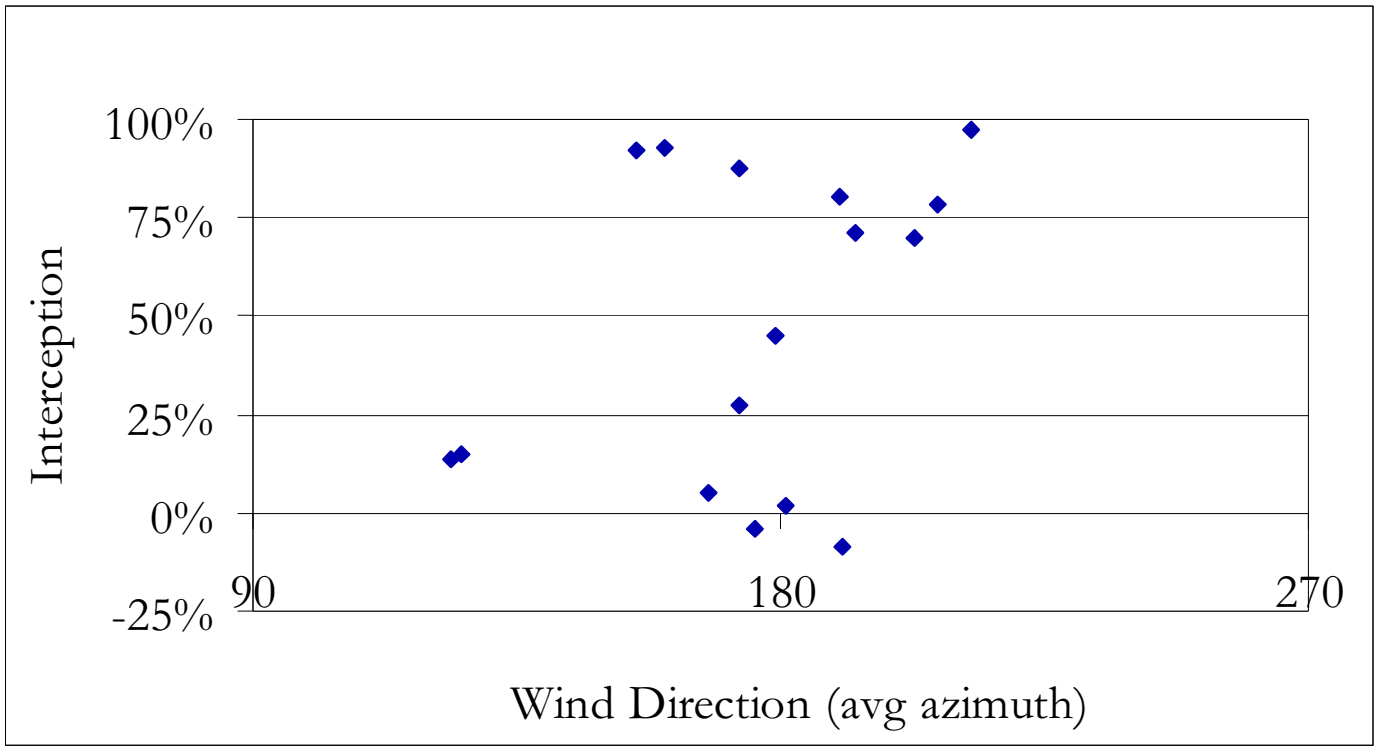

Figure 16. Average Wind Direction of Sixteen Isolated Storms. Average hourly wind directions compiled over the length of each isolated storm show southerly winds prevailing.

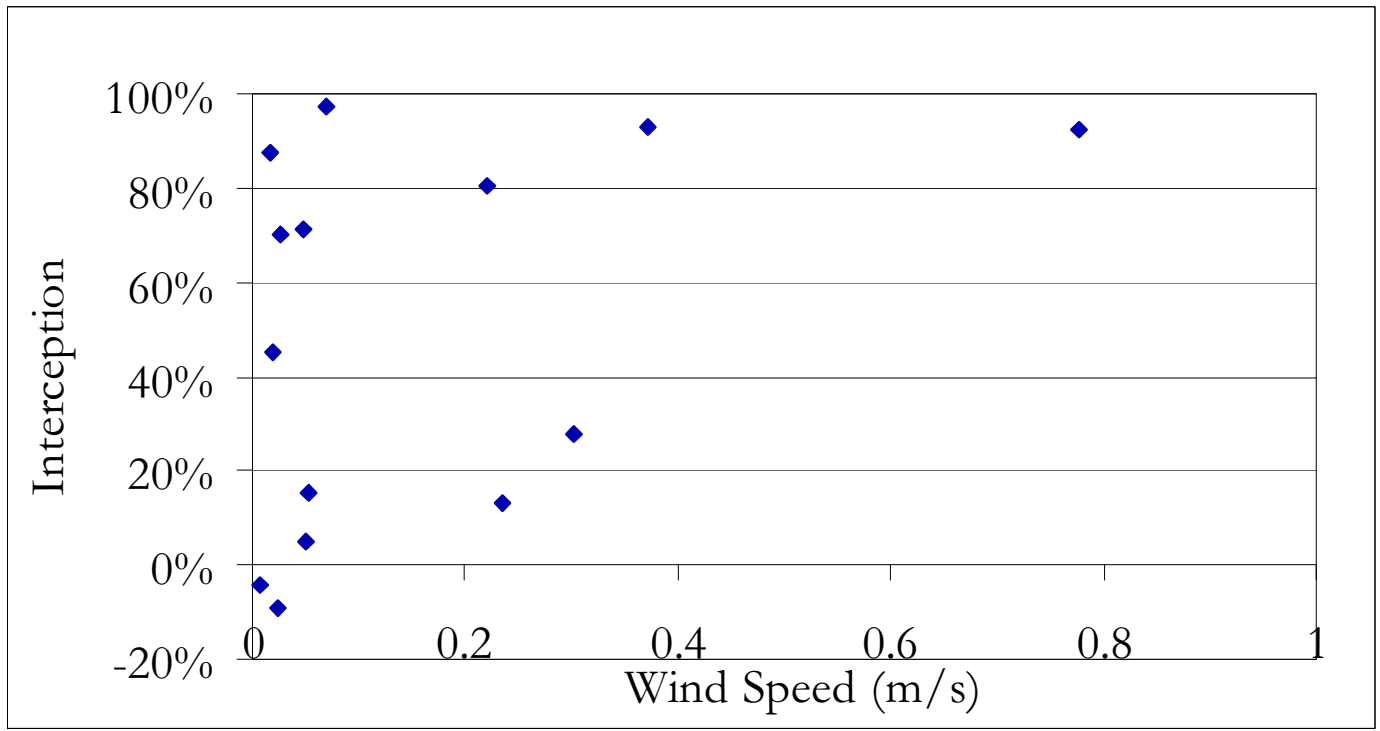

Figure 17. Average Wind Speed of Sixteen Isolated Storms. Average hourly wind speeds $(\mathrm{m} / \mathrm{s})$ compiled over the length of each isolated storm. 


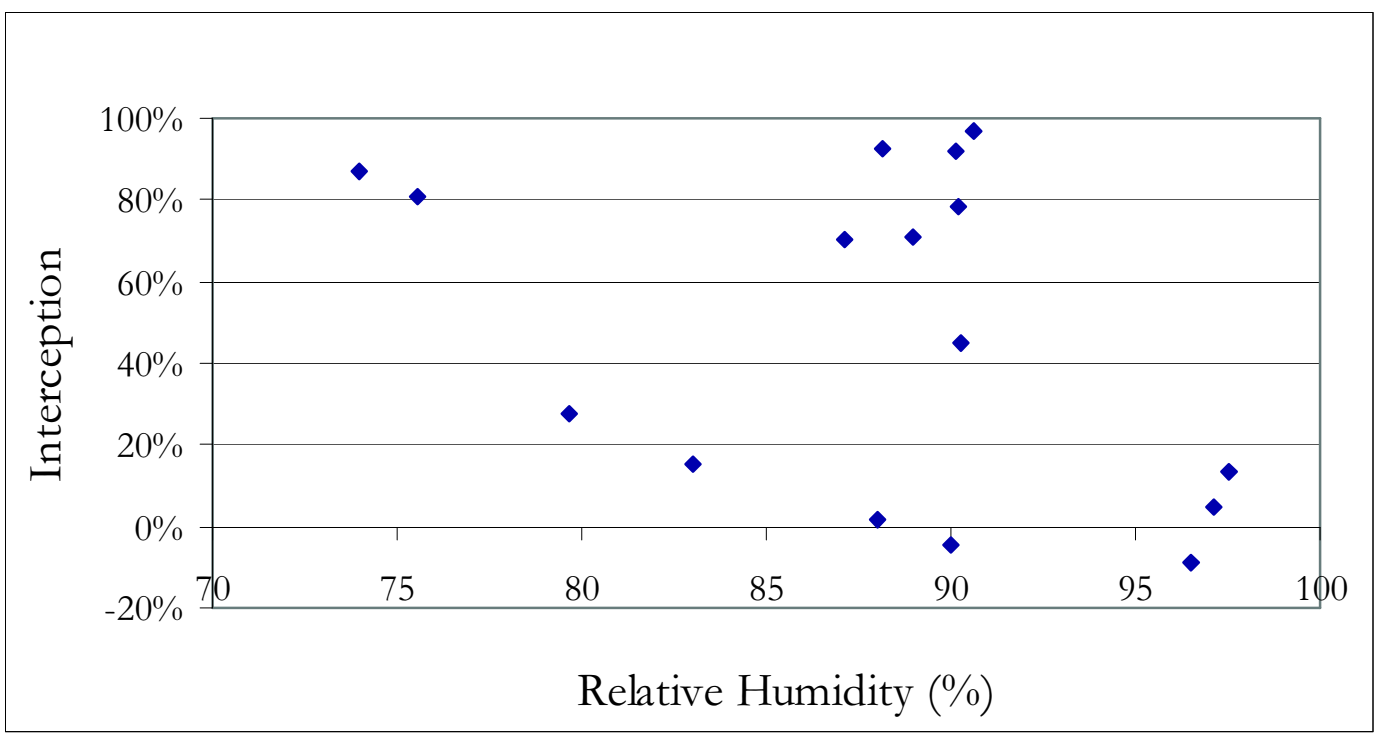

Figure 18. Average Relative Humidity of Sixteen Isolated Storms. Average relative humidity (\%) compiled over the length of each isolated storm.

$\underline{\text { Interception results }}$

As shown in Figure 19, the study period-long interception of the open-grown trees ranged widely, including one tree that averaged well below expected values, one tree at a level near closed-canopy values, and two trees performing well above closedcanopy. The average interception rate of the open-grown trees was $31 \%$, whereas the closed-canopy trees averaged 26\%, similar to other studies (Link 2004, Pypker 2005). 


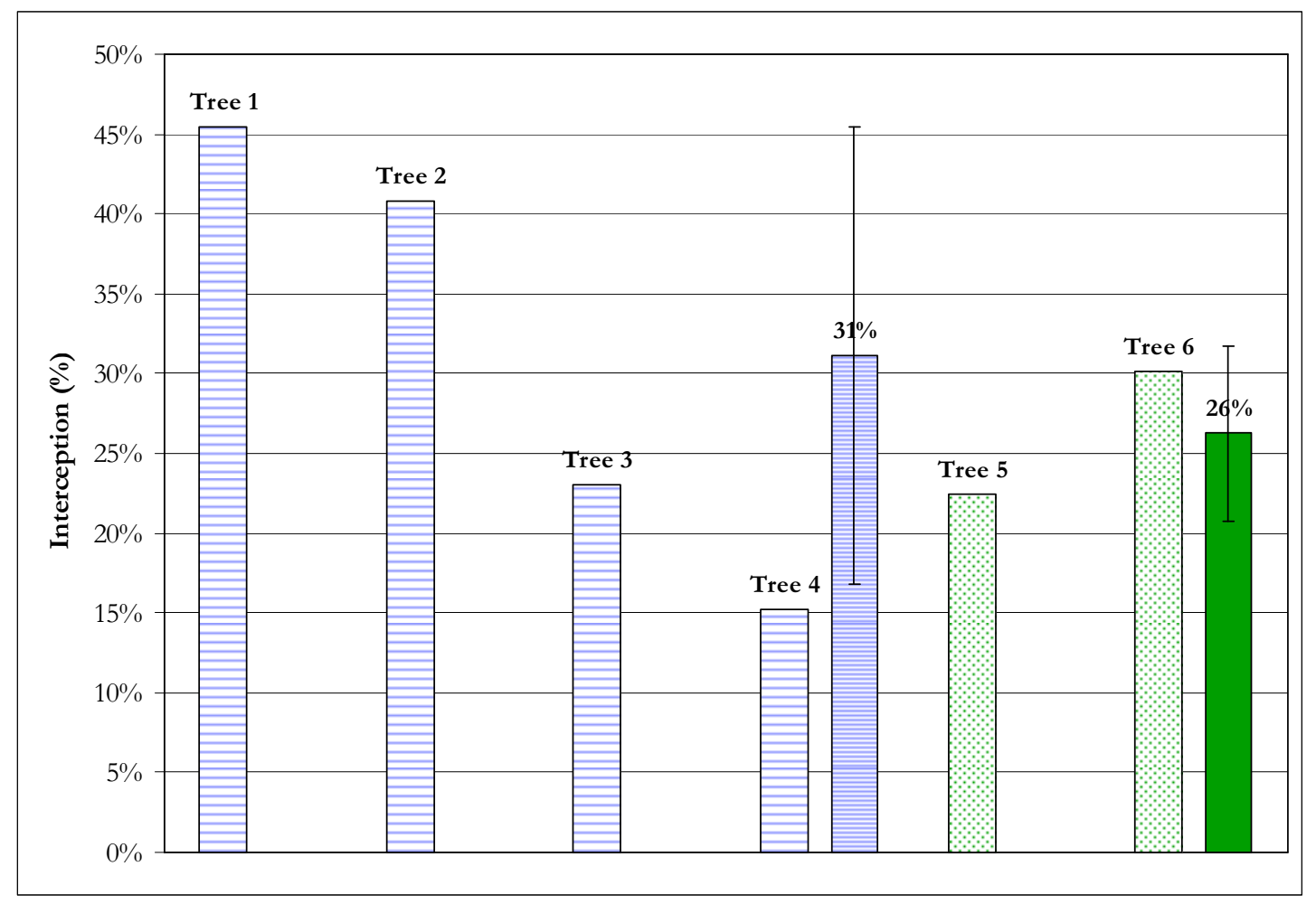

Figure 19. Study-long Interception for Each Study Tree. Trees 1-4 were opengrown trees, with interception ranging from $15-45 \%$, with overall average of $31 \%$ (diagonal lines). Trees $5 \& 6$ were closed-canopy trees, with interception of $22 \%$ and $30 \%$, with an overall average of $26 \%$ (horizontal lines). All interception values were determined using local (open-field) rainfall data. Error bars show standard deviation on open-grown and closed-canopy summary bars.

Interception values varied slightly with the raingauge used; see Appendix B for discussion of raingauges. For the purposes of local interception, the local, open-field gauges were used; they are the basis for the overall summary (Figure 19) as well as the summaries of individual trees (Figures $20 \& 21$ ). Interception values for all trees were generally low in November and March, and high in December, January and February. The study period-long pattern of interception by open-grown trees reflected that by closed-canopy trees. 

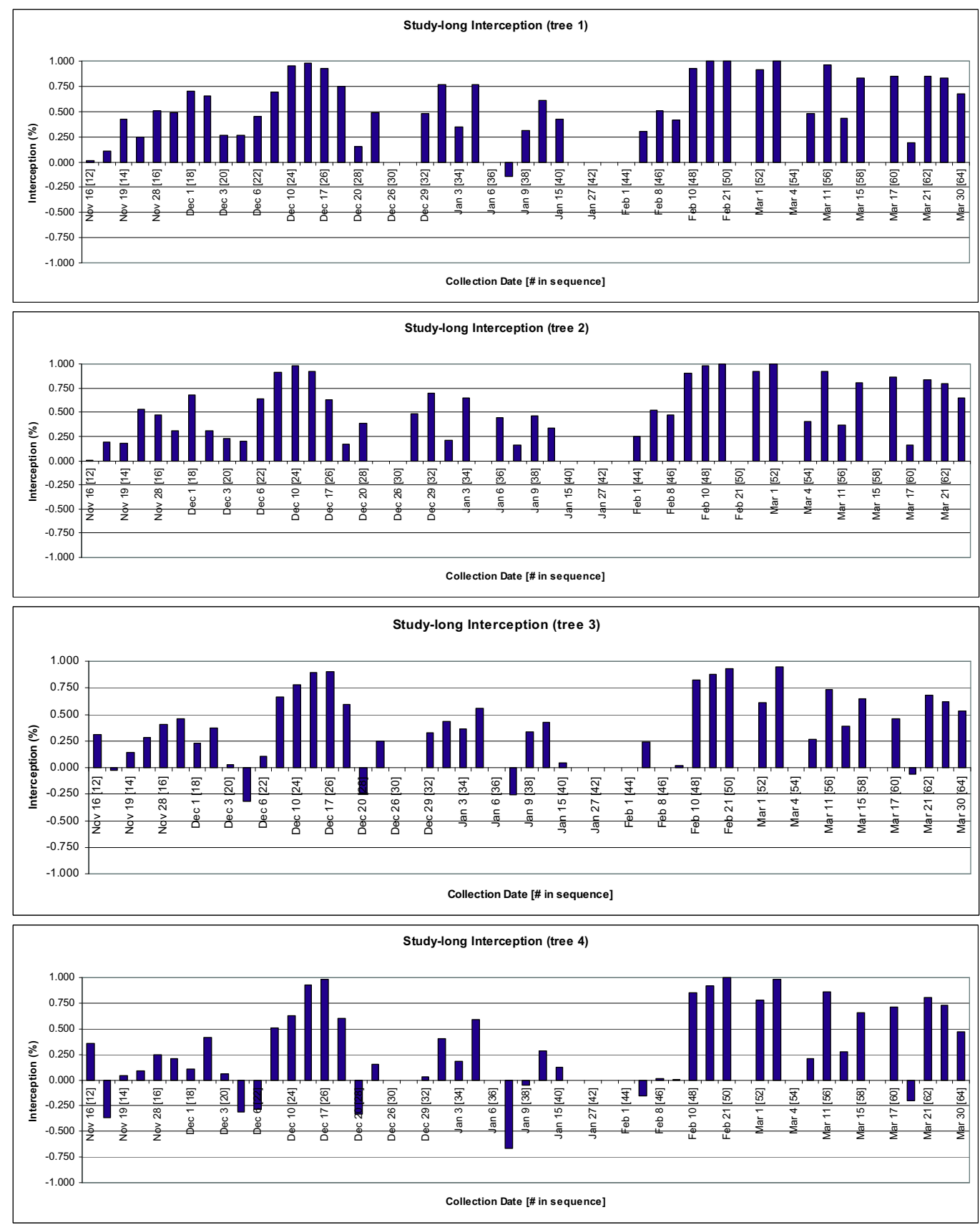

Figure 20. Study-long Interception of Open-grown Trees. Each panel shows the interception one of the four open-grown trees for all collections, starting with \#12 on 12Nov2007 and ending with \#64 on 30Mar2008, but excluding collections with multiple missing data. 


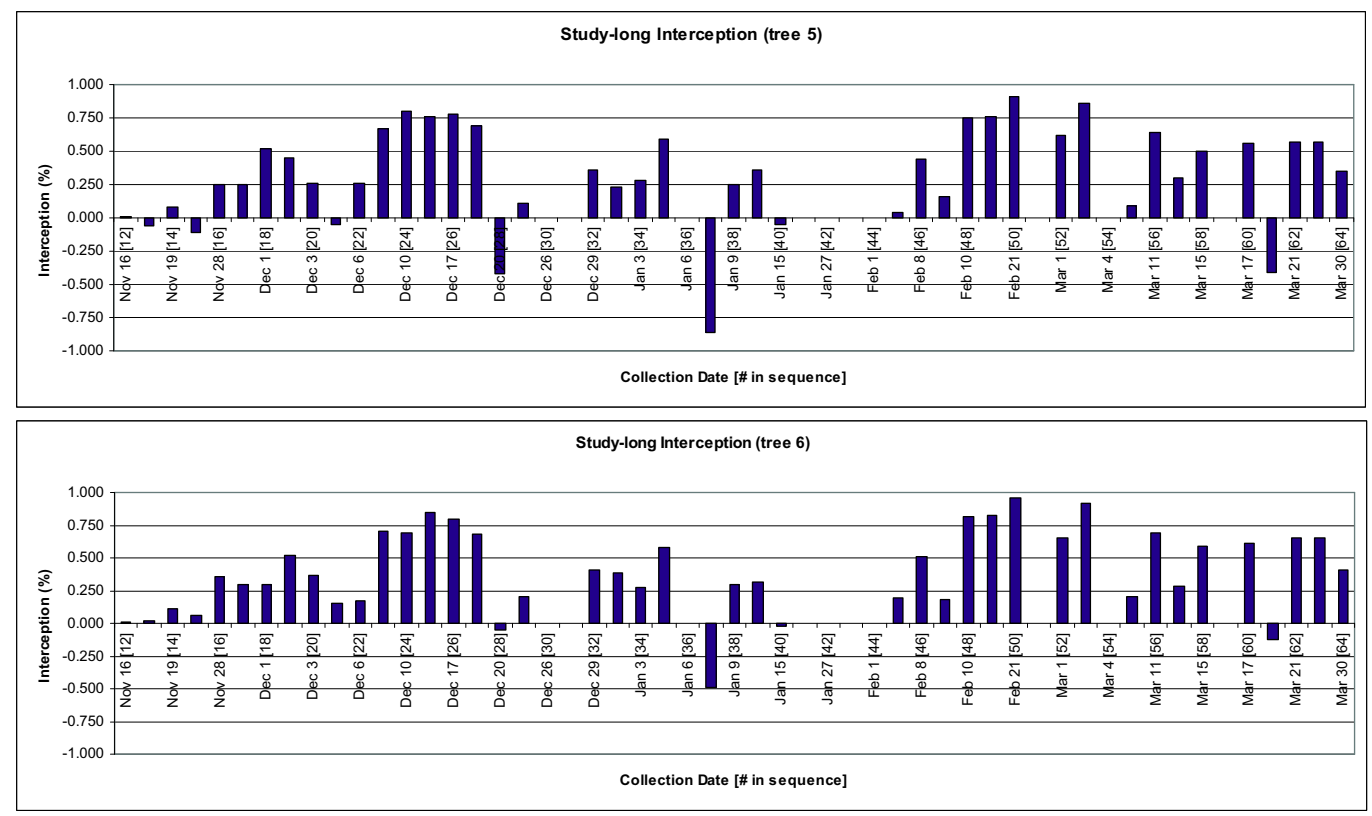

Figure 21. Study-long Interception of Closed-canopy Trees. Each panel shows the interception of both closed-canopy trees for all collections, starting with \#12 on 12Nov2007 and ending with \#64 on 30Mar2008, but excluding collections with multiple bucket failures. 


\section{Discussion}

\section{$\underline{\text { Error and precision }}$}

The raw data are composed of 64 collections at each of 36 collecting buckets. Collection periods ranged in length from 18 to 197 hours. Measurements were ultimately made using either a $100-\mathrm{mL}$ or a $1000-\mathrm{mL}$ graduated cylinder. Given the use of the $1000-\mathrm{mL}$ graduated cylinder, data will have precision of $10 \mathrm{~mL}$. The larger storms will have a correspondingly larger amount of error, due to the number of times necessary to pour larger volumes. Other sources of error led to "irregularities," or incidental missing data. Those sources include ice, snow, errors in technique and human interference. I have tried to account for these by excluding data from collections known to have irregularities. For example, six collections in January were removed because of ice; four were removed because of vandalism. My study benefitted from having several trees of a single species in one location; sources of error such as topography and microclimate were minimized.

\section{$\underline{\text { Variation in interception }}$}

Larger leaf area did not correspond to higher interception (Table 2), as might be expected. Tree 1 was the shortest tree of the four, with smallest diameter and smallest leaf area $\left[66.1 \mathrm{~m}^{2}\right]$. Yet, its interception totals were the highest of the group. Tree 2, with the largest leaf area $\left[93.0 \mathrm{~m}^{2}\right]$, yielded similar, slightly lower rates of interception. Interception at tree 3 seemed not to differ much from that of closed- 
canopy trees, despite a leaf area of $\left[69.5 \mathrm{~m}^{2}\right]$, while tree 4 , with slightly larger area than tree $1\left[70.9 \mathrm{~m}^{2}\right]$, allowed a noticeably larger amount of rain through its canopy.

Something is clearly different in the branch structure of tree 4 . It may be that the pixel method was not giving an accurate representation of canopy, or that the tree's particular location received more rainfall or allowed more to fall into the buckets at an angle. A weather station at that site, while costly and prone to vandalism, would allow a more accurate picture of local weather to be drawn. Another strong possibility is that tree 4 is less densely branched, allowing more rain to fall through. A photographic comparison (Figure 2) of the four open-grown trees suggests a more open canopy in tree 4, perhaps leading to lower interception values. Future interception studies of open grown trees would benefit from a detailed analysis of canopy morphology.

\section{Greater-than-incident rainfall}

In larger rain events, three buckets (\#18 [tree 3], \#21 [tree 4], and \#30 [tree 5]) recorded more water caught than fell in the open. In Link's (2004) buckets, 23\% recorded such an event, so it is not uncommon. Several possible explanations exist. The first explanation is that the buckets were placed too far out from under the canopy. All buckets were some distance from the trunk, although the determination of the canopy's edge at the time of bucket placement was somewhat conservative. A more definite means of determining canopy edge would mitigate this issue. 
A second explanation might be that the buckets sat at a drip point, and received throughfall falling outside the vertical cylinder it was intended to represent. This phenomenon is the reason why many buckets are necessary for good statistical analysis: some buckets may get a relatively large amount of water, while others get much less. During the largest storm, I observed that bucket 30 sat at a very pronounced drip point, explaining its substantial catches. Increasing the number of buckets under each tree would help smooth out the extreme results. Rotating the buckets to new locations was another common technique in closed-canopy studies, though it proved impractical in an open-grown study (Gash 1979, Pypker 2005).

A third possible explanation is aspect. All three of the buckets in question were positioned on the downhill portion of the tree, which in my study also gave them a more southerly position. The Hoyt weather station shows that our sample storms tended to be southerly, though this could be an artifact of the weather station station's placement; wind data at the trees would be necessary to be certain. If storms are tending southerly, then their leading edges would be falling on that side of the tree, which might, in turn, cause water to "pile up" in those buckets. In that case, one might expect all southerly buckets to show this pattern, but they do not. More than likely, a combination of these factors accounts for the greater-than-incident collections. 


\section{Historical vs. field data}

The rain regime during my study appeared to shift towards the lower end of the intensity spectrum (Figure 14). The result suggests that in more average years, interception might be lower, because rain tended to be more intense. Intensity was correlated inversely with interception $\left(\mathrm{R}^{2}=0.84\right)$ so my interception rates may actually be on the high side, but further study would be necessary to confirm this.

\section{Further Study}

There is substantial interest in the topic of urban interception, mostly from a purely practical standpoint, though interception's role in an urban hydrologic scheme still requires further attention. This study demonstrated the possibility of increasing interception in cities, and at the same time highlights some of the challenges and unanswered questions about how to fully quantify this process. Still to be addressed are the abilities of deciduous trees, though lacking foliage for several months, as well as other conifers. The role of microclimate in a given tree's interception capacity has been hinted at, but still needs systematic treatment. And, perhaps most importantly, the idea that spacing improves interception needs to be tested at more length. A single year's investigation cannot capture the full range of interception, and so a multi-annual study that accounts for climate variability would be desirable. 


\section{Management Implications}

The interception rates for open-grown Douglas-firs are encouraging, with an average open-grown rate of $31 \%$, as compared to an average closed-canopy rate of $26 \%$. The variability of interception rates for the open-grown trees is an intriguing finding for future study. The wide variation in canopy morphology of open grown trees likely plays an important role in an given tree's interception capacity.

If one continues from the premise of my study that open-grown Douglas-fir intercepts at least as well as closed-canopy Douglas-firs, and likely more, then their usefulness in mitigating urban stormwater runoff might be re-assessed. As a species, Douglas-fir already comprises an important part of the urban forest, particularly in parks and in off-street locations. The rainwater that these trees intercept and block entering a city's stormwater system in cities in the Pacific Northwest west of the Cascades is already substantial. If, on the other hand, Douglas-fir is not seen as a preferred species for further planting in some locations (e.g. in parking strips adjacent to city streets), then I have at least provided an approach for gauging which other species might be preferred. 


\section{Conclusion}

My study findings support the hypothesis that open-grown Douglas-firs intercept more rain than closed-canopy Douglas-firs. The mean interception rate for 5 month winter study period was higher for open grown trees than for nearby closed canopy. On an individual tree basis, half of the open-grown trees I examined had interception rates substantially higher than nearby closed-canopy trees. The interception values for closed canopy trees in the study were representative of Douglas-fir canopies, as suggested by other researchers. The range of interception results in open grown Douglas-fir trees was likely tied to the inherent variability in tree architecture, such as leaf area or branch density. At the same time, I have shown that separation of trees in some cases does result in an increased interception capacity. These findings could have direct implications for stormwater management, leading to the planting of more Douglas-fir with wide spacing, or indirect implications, as other species are tested for their interception capacities. 


\section{References}

Aston, A. R. 1979. Rainfall interception by eight small trees. Journal of Hydrology 42:383-396.

Del Rio, E., and A. Berg. 1979. Specific leaf area of Douglas-fir reproduction as affected by light and needle age. Forest Science 25:183-186.

Dingman, S. L. 2002. Physical Hydrology., 2nd edition. Prentice-Hall, Inc., Upper Saddle River, NJ.

Environmental Services, Portland [OR] Bureau of. 2011. Grey-to-Green Street Trees on 5/19/11 at http://www.portlandonline.com/bes/index.cfm?c=50795.

Ford, E. D., and J. D. Deans. 1978. The effects of canopy structure on stemflow, throughfall and interception loss in a young Sitka spruce plantation. Journal of Applied Ecology 15:905-917.

Gash, J. H. C. 1979. An analytical model of rainfall interception by forests. Quarterly Journal of the Royal Meterological Society 105:43-55.

Gash, J. H. C., C. R. Lloyd, and G. Lachaud. 1995. Estimating sparse forest rainfall interception with an analytical model. Journal of Hydrology 170:79-86.

Godfree, R. C. 2000. Lodgepole pine dwarf mistletoe (Arceuthobium americanum) in central Oregon lodgepole pine (Pinus contorta var. murrayana) stands: effects on crown architecture, population dynamics, canopy structure and understory composition. Portland State University, Portland, Oregon.

Helvey, J. D., and J. H. Patric. 1965. Canopy and litter interception of rainfall by hardwoods of eastern United States. Water Resources Research 1:193-206.

Hormann, G., A. Branding, T. Clemen, M. Herbst, A. Hinrichs, and F. Thamm. 1996. Calculation and simulation of wind controlled canopy interception of a beech forest in Northern Germany. Agricultural and Forest Meteorology. 79:131-148.

Horn, H. 1971. The adaptive geometry of trees. Princeton University Press, Princeton, N.J.

Horton, R. E. 1919. Rainfall interception. Monthly Weather Review 47:603-623.

Ishii, H., J. H. Reynolds, E. D. Ford, and D. C. Shaw. 2000. Height growth and vertical development of an old-growth Pseudotsuga-Tsuga forest in southwestern Washington State, U.S.A. Canadian Journal of Forest Research 30:17-24.

Jensen, E. C., and J. N. Long. 1983. Crown structure of a codominant Douglas-fir. Canadian Journal of Forest Research 13:264-269.

Johnson, D. M. 1987. Weather and Climate in Portland. Pages 20-37 in L. W. Price, editor. Portland's Changing Landscape. Department of Geography, Portland State University, Portland, OR.

Kimmins, J. P. 1973. Some statistical aspects of sampling throughfall precipitation in nutrient cycling studies in British Columbian coastal forests. Ecology 54:10081019. 
Kostelnik, K. M., J. A. Lynch, J. W. Grimm, and E. S. Corbett. 1989. Sample size requirements for estimation of throughfall chemistry beneath a mixed hardwood forest. Journal of Environmental Quality 18:274-280.

Lankreijer, H. J. M., M. J. Hendriks, and W. Klaasen. 1993. A comparison of models simulating rainfall interception of forests. Agricultural and Forest Meteorology 64:187-199.

Link, T. E., M. Unsworth, and D. Marks. 2004. The dynamics of rainfall interception by a seasonal temperate rainforest. Agricultural and Forest Meteorology. 124:171-191.

Liu, S. 1997. A new model for the prediction of rainfall interception in forest canopies. Ecological Modelling 99:151-159.

Liu, S. 2001. Evaluation of the Liu model for predicting rainfall interception in forests world-wide. Hydrological Processes 15:2341-2360.

Lloyd, C. R., J. H. C. Gash, and W. J. Shuttleworth. 1988. The measurement and modeling of rainfall interception by Amazonian rain forest. Agricultural and Forest Meteorology 43:277-294.

Makela, A. 1997. A carbon balance model of growth and self-pruning in trees based on structural relationships. Forest Science 43:7-24.

McPherson, E. G., J. R. Simpson, P. J. Peper, S. E. Maco, and Q. Xiao. 2005. Municipal forest benefits and costs in five U.S. cities. Journal of Forestry:411416.

McPherson, E. G., J. R. Simpson, P. J. Peper, and Q. Xiao. 1999. Benefit-cost analysis of Modesto's municipal urban forest. Journal of Arboriculture 25:235-248.

Mulder, J. P. M. 1985. Simulating interception loss using standard meteorological data. Pages 177-196 in B. A. Hutchison and B. B. Hicks, editors. The ForestAtmosphere Interaction. D. Reidel Publishing Company, Dordrecht, The Netherlands.

Peper, P. J., and E. G. McPherson. 2003. Evaluation of four methods for estimating leaf area of isolated trees. Urban Forestry \& Urban Greening 2:19-29.

Price, A. G., and D. E. Carlyle-Moses. 2003. Measurement and modeling of growingseason canopy water fluxes in a mature mixed deciduous forest stand, southern Ontario, Canada. Agricultural and Forest Meteorology 119:69-85.

Puckett, L. J. 1991. Spatial variability and collector requirements for sampling throughfall volume and chemistry under a mixed-hardwood canopy. Canadian Journal of Forest Research 21:1581-1588.

Pypker, T. G., B. J. Bond, T. E. Link, D. Marks, and M. H. Unsworth. 2005. The importance of canopy structure in controlling the interception loss of rainfall: Examples from a young and an old-growth Douglas-fir forest. Agricultural and Forest Meteorology. 130:113-129.

Reynolds, B., and C. Neal. 1991. Trough versus funnel colllectors for measuring throughfall volumes. Journal of Environmental Quality 20:518-521. 
Rothacher, J. 1963. Net precipitation under a Douglas-fir forest. Forest Science 9:423429.

Rutter, A. J., K. A. Kershaw, P. C. Robins, and A. J. Morton. 1971. A predictive model of rainfall interception in forests; 1 . Derivation of the model from observations in a plantation of Corsican pine. Agricultural Meteorology 9:367384.

Sanders, R. A. 1986. Urban vegetation impoacts of the hydrology of Dayton, Ohio. Urban Ecology 9:361-376.

St. Clair, J. B. 1994. Genetic variation in tree structure and its relation to size in Douglas-fir. II. Crown form, branch characters, and foliage characters. Canadian Journal of Forest Research 24:1236-1247.

Takahashi, K. 1996. Plastic response of crown architecture to crowding in understory trees of two co-dominating conifers. Annals of Botany 77:159-164.

Taylor, G. Personal communication, March 2007. Oregon Climate Service (Oregon State University).

Teklehaimanot, Z., P. G. Jarvis, and D. C. Ledger. 1991. Rainfall interception and boundary layer conductance in relation to tree spacing. Journal of Hydrology 123:261-278.

Voigt, G. K. 1961. Distribution of rainfall under forest stands. Forest Science 6:2-10.

Walsh, C. J., T. D. Fletcher, and A. R. Ladson. 2005. Stream restoration in urban catchments through redesigning stormwater systems: looking to the catchment to save the stream. Journal of the North American Benthological Society 24:690-705.

Xiao, Q., and E. G. McPherson. 2003. Rainfall interception by Santa Monica's municipal urban forest. Urban Ecosystems 6:291-302.

Xiao, Q., E. G. McPherson, S. L. Ustin, and M. E. Grismer. 2000a. A new approach to modeling tree rainfall interception. Journal of Geophysical Research 105:29, 173-129,188.

Xiao, Q., E. G. McPherson, S. L. Ustin, M. E. Grismer, and J. R. Simpson. 2000b. Winter rainfall interception by two mature open-grown trees in Davis, California. Hydrological Processes 14:763-784.

Zinke, P. 1965. Forest interception studies in the United States. Pages 137-161 in W. Sopper and H. Lull, editors. Forest hydrology: the proceedings of a National Science Foundation advanced seminar at the Pennsylvania State University.... Pergamon Press, Pennsylvania State University. 


\begin{tabular}{|c|c|c|c|c|c|c|c|c|}
\hline \multicolumn{9}{|c|}{ Appendix A: Rainfall Depths Per Bucket in cm (vol/area) } \\
\hline & Nov 16 & Nov 17 & Nov 19 & Nov 20 & Nov 28 & Nov 29 & Dec 1 & Dec 2 \\
\hline break & $\underline{12}$ & $\underline{13}$ & $\underline{14}$ & $\underline{15}$ & $\underline{16}$ & $\underline{17}$ & $\underline{18}$ & 19 \\
\hline \multirow[t]{7}{*}{ tree 1} & 0.603 & 3.547 & 1.756 & 0.689 & 0.405 & 0.913 & 0.189 & 0.448 \\
\hline & 0.792 & 2.782 & 1.725 & 0.563 & 0.546 & 0.827 & 0.176 & 0.651 \\
\hline & 0.745 & 2.164 & 1.552 & 0.532 & 0.532 & 0.763 & 0.098 & 0.834 \\
\hline & & 2.776 & 1.454 & 0.568 & 0.692 & 1.011 & 0.035 & 0.949 \\
\hline & 0.947 & 1.707 & 1.063 & 0.340 & 0.429 & 0.572 & 0.045 & 0.500 \\
\hline & & 2.555 & 1.474 & 0.509 & 0.590 & 0.724 & 0.054 & 0.554 \\
\hline & 0.772 & 2.588 & 1.504 & 0.533 & 0.532 & 0.802 & 0.099 & 0.656 \\
\hline \multirow{7}{*}{ tree 2} & & 2.984 & 2.073 & 0.643 & 0.581 & 0.858 & 0.357 & 0.581 \\
\hline & 0.411 & 3.342 & 2.752 & 0.625 & & 0.983 & 0.322 & 0.554 \\
\hline & 1.348 & 3.033 & 2.093 & 0.692 & 0.665 & 1.002 & 0.204 & 0.958 \\
\hline & 0.920 & 1.653 & 0.849 & 0.295 & 0.384 & 0.482 & 0.045 & 0.643 \\
\hline & 0.697 & 3.306 & 2.627 & 0.661 & 0.411 & 0.929 & 0.223 & 0.447 \\
\hline & 0.958 & 2.980 & 2.199 & 0.568 & 0.443 & 0.709 & 0.231 & 0.594 \\
\hline & 0.867 & 2.883 & 2.099 & 0.581 & 0.497 & 0.827 & 0.230 & 0.629 \\
\hline \multirow[t]{2}{*}{ OF Gauge 1} & & 2.908 & 2.602 & 0.711 & 1.071 & 1.557 & 0.333 & 1.926 \\
\hline & & & & & & & & \\
\hline \multirow[t]{7}{*}{ tree 5} & 0.885 & 1.943 & 1.301 & 0.338 & 0.399 & 0.598 & 0.069 & 0.598 \\
\hline & 1.561 & 3.296 & 2.515 & 0.746 & 0.876 & 1.388 & 0.269 & 0.885 \\
\hline & 4.328 & 4.097 & 3.130 & 1.481 & 1.224 & 1.348 & 0.115 & 2.288 \\
\hline & 1.471 & 3.400 & 2.806 & 0.713 & 0.749 & 1.426 & 0.155 & 0.850 \\
\hline & 1.519 & 2.850 & 2.252 & 0.733 & 0.715 & 0.983 & 0.214 & 0.893 \\
\hline & 1.653 & 2.931 & 2.287 & 0.715 & 0.876 & 1.260 & 0.143 & 0.893 \\
\hline & 1.903 & 3.086 & 2.382 & 0.788 & 0.806 & 1.167 & 0.161 & 1.068 \\
\hline \multirow{9}{*}{ tree 6} & & & & & & & & \\
\hline & 1.386 & 3.151 & 2.422 & 0.684 & 0.738 & 1.242 & 0.180 & 1.008 \\
\hline & 1.452 & 3.195 & 2.764 & 0.572 & 0.651 & 1.039 & 0.282 & 0.766 \\
\hline & & 3.048 & 2.338 & 0.711 & 0.739 & 1.141 & 0.224 & 1.085 \\
\hline & 1.578 & 2.404 & 1.669 & 0.599 & 0.635 & 0.943 & 0.245 & 0.853 \\
\hline & 1.544 & 2.446 & 2.342 & 0.668 & 0.737 & 1.180 & 0.252 & 0.919 \\
\hline & 1.408 & 2.887 & 2.377 & 0.757 & 0.634 & 1.047 & 0.229 & 0.863 \\
\hline & 1.474 & 2.855 & 2.318 & 0.665 & 0.689 & 1.099 & 0.235 & 0.916 \\
\hline & & & & & & & & \\
\hline
\end{tabular}




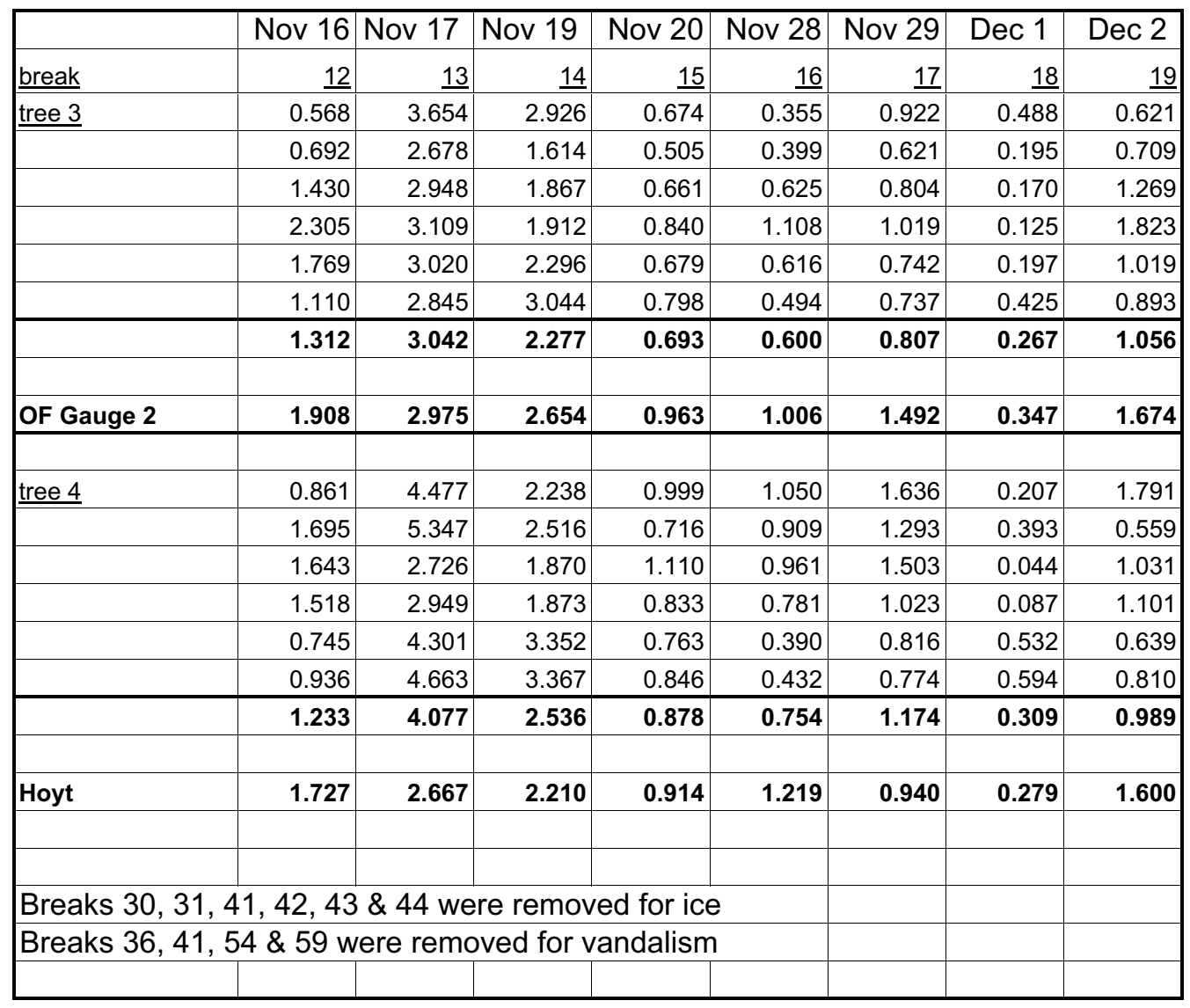




\begin{tabular}{|c|c|c|c|c|c|c|c|c|}
\hline \multicolumn{9}{|c|}{ Appendix A: } \\
\hline & Dec 3 & $\operatorname{Dec} 4$ & $\operatorname{Dec} 6$ & $\operatorname{Dec} 7$ & Dec 10 & Dec 15 & Dec 17 & Dec 19 \\
\hline break & $\underline{20}$ & $\underline{21}$ & $\underline{22}$ & $\underline{23}$ & $\underline{24}$ & $\underline{25}$ & $\underline{26}$ & $\underline{27}$ \\
\hline \multirow[t]{7}{*}{$\overline{\text { tree } 1}$} & 7.266 & 1.007 & 0.878 & 0.069 & 0.017 & 0.005 & 0.069 & 0.930 \\
\hline & 10.862 & 1.523 & 0.748 & 0.026 & 0.009 & 0.005 & 0.032 & 0.898 \\
\hline & 8.043 & 1.082 & 0.505 & 0.027 & 0.002 & 0.009 & 0.067 & 0.505 \\
\hline & 10.863 & 1.543 & 0.443 & 0.035 & 0.002 & 0.016 & 0.053 & 0.426 \\
\hline & 6.308 & 0.920 & 0.348 & 0.027 & 0.005 & 0.002 & 0.005 & 0.205 \\
\hline & 6.603 & 0.983 & 0.438 & 0.045 & 0.005 & 0.004 & 0.014 & 0.384 \\
\hline & 8.324 & 1.176 & 0.560 & 0.038 & 0.007 & 0.007 & 0.040 & 0.558 \\
\hline & & & & & & & & \\
\hline \multirow[t]{7}{*}{ tree 2 } & 8.095 & 1.340 & 0.876 & 0.036 & 0.018 & 0.007 & 0.054 & 1.135 \\
\hline & 8.550 & 1.197 & 1.197 & 0.054 & 0.009 & 0.014 & 0.080 & 1.045 \\
\hline & 9.808 & 1.366 & 0.665 & 0.053 & 0.009 & 0.009 & 0.050 & 0.683 \\
\hline & 7.952 & 1.278 & 0.348 & 0.027 & 0.005 & 0.005 & 0.014 & 0.590 \\
\hline & 6.540 & 1.108 & 0.893 & 0.063 & 0.018 & 0.002 & 0.018 & 0.733 \\
\hline & 6.562 & 1.117 & 0.931 & 0.044 & 0.018 & 0.011 & 0.035 & 0.851 \\
\hline & 7.918 & 1.234 & 0.819 & 0.046 & 0.013 & 0.008 & 0.042 & 0.839 \\
\hline & & & & & & & & \\
\hline OF Gauge 1 & 11.369 & 1.593 & 1.017 & 0.126 & 0.144 & 0.342 & 0.510 & 2.241 \\
\hline \multirow[t]{7}{*}{ tree 5} & 4.536 & 0.945 & 0.486 & 0.035 & 0.035 & 0.043 & 0.071 & 0.416 \\
\hline & 7.094 & 1.362 & 0.963 & 0.035 & 0.035 & 0.083 & 0.139 & 0.859 \\
\hline & 14.907 & 3.813 & 0.568 & 0.044 & 0.027 & 0.122 & 0.140 & 0.727 \\
\hline & 10.692 & 1.261 & 0.877 & 0.055 & 0.027 & 0.099 & 0.128 & 0.621 \\
\hline & 7.166 & 1.430 & 0.983 & 0.045 & 0.036 & 0.077 & 0.098 & 0.840 \\
\hline & 6.263 & 1.233 & 0.625 & 0.036 & 0.018 & 0.073 & 0.089 & 0.733 \\
\hline & 8.443 & 1.674 & 0.750 & 0.041 & 0.030 & 0.083 & 0.111 & 0.699 \\
\hline & & & & & & & & \\
\hline \multirow[t]{8}{*}{ tree 6} & 8.066 & 1.458 & 0.954 & 0.036 & 0.045 & $\begin{array}{l}0.043 \\
0.039\end{array}$ & \begin{tabular}{|l|}
0.140 \\
0.097
\end{tabular} & $\begin{array}{l}0.549 \\
0.810\end{array}$ \\
\hline & 5.924 & 1.118 & 1.039 & 0.044 & 0.062 & 0.039 & 0.097 & 0.810 \\
\hline & 8.144 & 1.552 & 0.842 & 0.047 & 0.037 & 0.086 & 0.116 & 0.655 \\
\hline & 6.975 & 1.243 & 0.689 & 0.027 & 0.036 & 0.042 & 0.091 & 0.644 \\
\hline & 7.407 & 1.353 & 0.763 & 0.035 & 0.035 & 0.061 & 0.075 & 0.763 \\
\hline & 6.470 & 1.347 & 0.757 & 0.035 & 0.053 & 0.048 & 0.092 & 0.836 \\
\hline & 7.164 & 1.345 & 0.841 & 0.037 & 0.045 & 0.053 & 0.102 & 0.709 \\
\hline & & & & & & & & \\
\hline
\end{tabular}




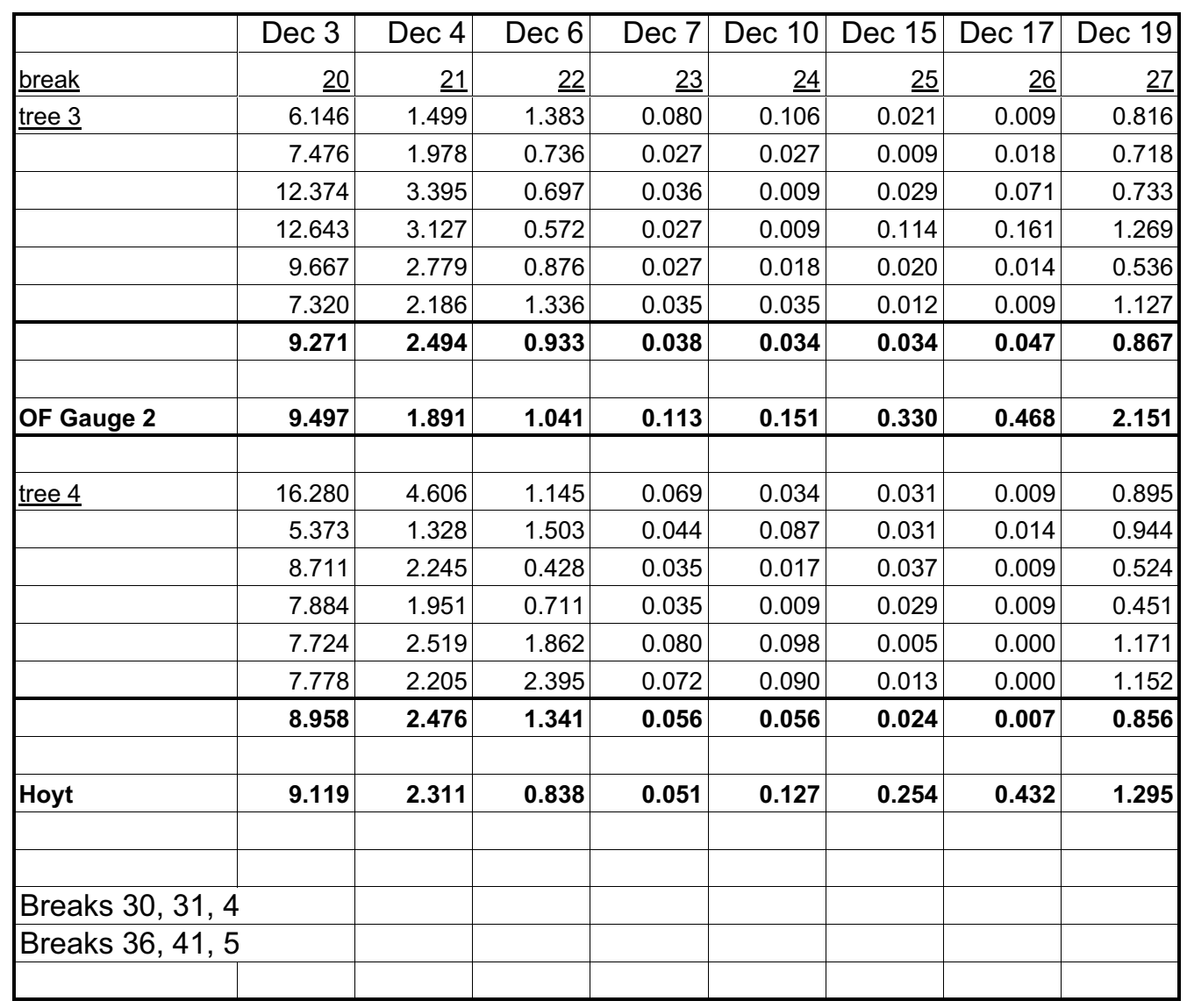




\begin{tabular}{|c|c|c|c|c|c|c|c|c|}
\hline \multicolumn{9}{|c|}{ Appendix A: } \\
\hline & Dec 20 & Dec 22 & Dec 26 & Dec 28 & Dec 29 & Dec 31 & Jan 3 & Jan 4 \\
\hline break & $\underline{28}$ & $\underline{29}$ & $\underline{30}$ & 31 & $\underline{32}$ & $\underline{33}$ & $\underline{34}$ & $\underline{35}$ \\
\hline \multirow[t]{7}{*}{$\overline{\text { tree } 1}$} & 1.093 & 0.689 & & & 0.456 & 0.189 & 2.419 & 0.241 \\
\hline & 1.382 & 0.792 & & & 0.405 & 0.194 & 2.368 & 0.290 \\
\hline & 1.188 & 0.736 & & & 0.408 & 0.302 & 1.295 & 0.390 \\
\hline & 2.297 & 1.215 & & & 0.603 & 0.461 & 2.057 & 0.426 \\
\hline & 1.072 & 0.768 & & & 0.357 & 0.304 & 0.965 & 0.331 \\
\hline & 1.465 & 0.867 & & & 0.411 & 0.348 & 2.234 & 0.348 \\
\hline & 1.416 & 0.844 & & & 0.440 & 0.300 & 1.890 & 0.338 \\
\hline & & & & & & & & \\
\hline \multirow[t]{8}{*}{$\underline{\underline{\text { tree } 2}}$} & 1.340 & 1.072 & & & 0.465 & 0.420 & 2.725 & 0.536 \\
\hline & 0.786 & 0.742 & & & 0.384 & 0.223 & 3.216 & 0.572 \\
\hline & 2.252 & 1.658 & & & 0.532 & 0.603 & 1.898 & 0.789 \\
\hline & 1.474 & 0.795 & & & 0.447 & 0.393 & 1.233 & 0.286 \\
\hline & 1.117 & 0.938 & & & 0.411 & 0.232 & 2.520 & 0.393 \\
\hline & 1.339 & 0.958 & & & 0.381 & 0.479 & 2.306 & 0.461 \\
\hline & 1.385 & 1.027 & & & 0.437 & 0.392 & 2.316 & 0.506 \\
\hline & & & & & & & & \\
\hline OF Gauge 1 & 1.665 & 1.665 & & & 0.846 & 1.296 & 2.917 & 1.440 \\
\hline \multirow[t]{8}{*}{$\underline{\underline{\text { tree } 5}}$} & 1.145 & 0.867 & & & 0.330 & 0.529 & 1.691 & 0.442 \\
\hline & 1.648 & 1.370 & & & 0.503 & 0.919 & 2.654 & 0.694 \\
\hline & 6.740 & 2.891 & & & 1.011 & 2.439 & 2.128 & 0.816 \\
\hline & 1.407 & 1.270 & & & 0.503 & 0.658 & 1.919 & 0.548 \\
\hline & 1.805 & 1.438 & & & 0.465 & 0.795 & 2.493 & 0.545 \\
\hline & 1.394 & 1.081 & & & 0.447 & 0.661 & 1.653 & 0.518 \\
\hline & 2.356 & 1.486 & & & 0.543 & 1.000 & 2.090 & 0.594 \\
\hline & & & & & & & & \\
\hline \multirow[t]{8}{*}{ tree 6} & 1.854 & 1.422 & & & 0.414 & 0.702 & 2.377 & 0.522 \\
\hline & 1.373 & 1.180 & & & 0.475 & 0.827 & 2.042 & 0.616 \\
\hline & 1.814 & 1.431 & & & 0.542 & 0.842 & 1.964 & 0.655 \\
\hline & 1.823 & 1.224 & & & 0.544 & 0.816 & 1.850 & 0.635 \\
\hline & 1.804 & 1.266 & & & 0.555 & 0.850 & 2.324 & 0.633 \\
\hline & 1.866 & 1.461 & & & 0.493 & 0.748 & 2.042 & 0.563 \\
\hline & 1.756 & 1.331 & & & 0.504 & 0.798 & 2.100 & 0.604 \\
\hline & & & & & & & & \\
\hline
\end{tabular}




\begin{tabular}{|l|r|r|r|r|r|r|r|r|}
\hline & Dec 20 & Dec 22 & Dec 26 & Dec 28 & Dec 29 & Dec 31 & Jan 3 & Jan 4 \\
\hline$\underline{\text { break }}$ & $\underline{28}$ & $\underline{29}$ & $\underline{30}$ & $\underline{31}$ & $\underline{32}$ & $\underline{33}$ & $\underline{34}$ & $\underline{35}$ \\
\hline$\underline{\text { tree 3 }}$ & 0.905 & 0.772 & & & 0.470 & 0.399 & 2.785 & 0.709 \\
\hline & 1.144 & 0.772 & & & 0.443 & 0.284 & 1.827 & 0.426 \\
\hline & 2.216 & 1.340 & & & 0.822 & 0.804 & 1.376 & 0.608 \\
\hline & 3.181 & 1.769 & & & 0.715 & 1.233 & 1.662 & 0.920 \\
\hline & 2.037 & 1.170 & & & 0.536 & 0.643 & 0.849 & 0.438 \\
\hline & & 1.110 & & & 0.442 & 0.590 & 2.168 & 0.659 \\
\hline & $\mathbf{1 . 8 9 6}$ & $\mathbf{1 . 1 5 5}$ & & & $\mathbf{0 . 5 7 1}$ & $\mathbf{0 . 6 5 9}$ & $\mathbf{1 . 7 7 8}$ & $\mathbf{0 . 6 2 7}$ \\
\hline & & & & & & & & \\
\hline & $\mathbf{1 . 5 3 5}$ & $\mathbf{1 . 5 3 5}$ & & & $\mathbf{0 . 8 5 0}$ & $\mathbf{1 . 1 6 2}$ & $\mathbf{2 . 8 0 1}$ & $\mathbf{1 . 4 0 5}$ \\
\hline & & & & & & & & \\
\hline & 3.323 & 2.152 & & & 1.722 & 1.102 & 3.513 & 0.895 \\
\hline & 1.057 & 0.900 & & & 0.419 & 0.507 & 2.953 & 0.550 \\
\hline & 2.272 & 1.415 & & & 0.725 & 0.786 & 1.983 & 0.751 \\
\hline & 2.108 & 1.249 & & & 0.624 & 1.006 & 1.388 & 0.555 \\
\hline & 1.774 & 1.100 & & & 0.754 & 0.310 & 2.306 & 0.302 \\
\hline & 1.692 & 1.017 & & & 0.666 & 0.450 & 1.656 & 0.378 \\
\hline & $\mathbf{2 . 0 3 8}$ & $\mathbf{1 . 3 0 6}$ & & & $\mathbf{0 . 8 1 8}$ & $\mathbf{0 . 6 9 4}$ & $\mathbf{2 . 3 0 0}$ & $\mathbf{0 . 5 7 2}$ \\
\hline & & & & & & & & \\
\hline & $\mathbf{1 . 9 3 0}$ & $\mathbf{0 . 5 8 4}$ & & & $\mathbf{1 . 6 5 1}$ & $\mathbf{1 . 0 6 7}$ & $\mathbf{2 . 4 3 8}$ & $\mathbf{1 . 2 7 0}$ \\
\hline & & & & & & & & \\
\hline & & & & & & & & \\
\hline & & & & & & & & \\
\hline Hoyt & & & & & & & & \\
\hline
\end{tabular}




\begin{tabular}{|c|c|c|c|c|c|c|c|c|}
\hline \multicolumn{9}{|c|}{ Appendix A: } \\
\hline & $\operatorname{Jan} 6$ & Jan 7 & Jan 9 & Jan 12 & Jan 15 & Jan 19 & Jan 27 & Jan 28 \\
\hline break & $\underline{36}$ & $\underline{37}$ & $\underline{38}$ & $\underline{39}$ & $\underline{40}$ & 41 & $\underline{42}$ & $\underline{43}$ \\
\hline \multirow[t]{8}{*}{$\overline{\text { tree } 1}$} & & 0.103 & 2.772 & 1.257 & 0.327 & & & \\
\hline & & 0.114 & 2.605 & 1.197 & 0.563 & & & \\
\hline & & 0.168 & 1.295 & 0.905 & 0.443 & & & \\
\hline & & 1.383 & 1.383 & 0.975 & 0.993 & & & \\
\hline & & 0.134 & 0.759 & 0.697 & 0.840 & & & \\
\hline & & 0.134 & 1.045 & 0.813 & 0.858 & & & \\
\hline & & 0.340 & 1.643 & 0.974 & 0.671 & & & \\
\hline & & & & & & & & \\
\hline \multirow[t]{7}{*}{ tree 2 } & & 0.143 & 2.305 & 1.644 & 0.849 & & & \\
\hline & & 0.071 & 1.662 & 1.519 & 0.474 & & & \\
\hline & & 0.248 & 1.153 & 1.242 & 0.869 & & & \\
\hline & & 0.304 & 2.609 & 0.840 & 0.733 & & & \\
\hline & & 0.071 & 1.894 & 1.367 & 0.911 & & & \\
\hline & & 0.151 & 2.394 & 1.383 & 0.851 & & & \\
\hline & & 0.165 & 2.003 & 1.332 & 0.781 & & & \\
\hline & & & & & & & & \\
\hline \multirow[t]{2}{*}{ OF Gauge 1} & & 0.297 & 2.395 & 2.503 & 1.170 & & & \\
\hline & & & & & & & & \\
\hline \multirow[t]{8}{*}{$\underline{\underline{\text { tree } 5}}$} & & 0.278 & 1.336 & 1.240 & 0.980 & & & \\
\hline & & 0.356 & 1.856 & 1.769 & 1.336 & & & \\
\hline & & 1.720 & 2.634 & 2.341 & 1.623 & & & \\
\hline & & 0.256 & 1.435 & 1.179 & 1.042 & & & \\
\hline & & 0.429 & 1.912 & 1.796 & 1.296 & & & \\
\hline & & 0.268 & 1.555 & 1.215 & 1.126 & & & \\
\hline & & 0.551 & 1.788 & 1.590 & 1.234 & & & \\
\hline & & & & & & & & \\
\hline \multirow[t]{8}{*}{ tree 6} & & 0.522 & 1.800 & 1.800 & 1.026 & & & \\
\hline & & 0.317 & 1.602 & 1.699 & 1.356 & & & \\
\hline & & 0.430 & 1.590 & 1.683 & 1.159 & & & \\
\hline & & 0.544 & 1.651 & 1.614 & 1.234 & & & \\
\hline & & 0.408 & 1.630 & 1.500 & 1.153 & & & \\
\hline & & 0.440 & 1.866 & 1.928 & 1.232 & & & \\
\hline & & 0.444 & 1.690 & 1.704 & 1.193 & & & \\
\hline & & & & & & & & \\
\hline
\end{tabular}




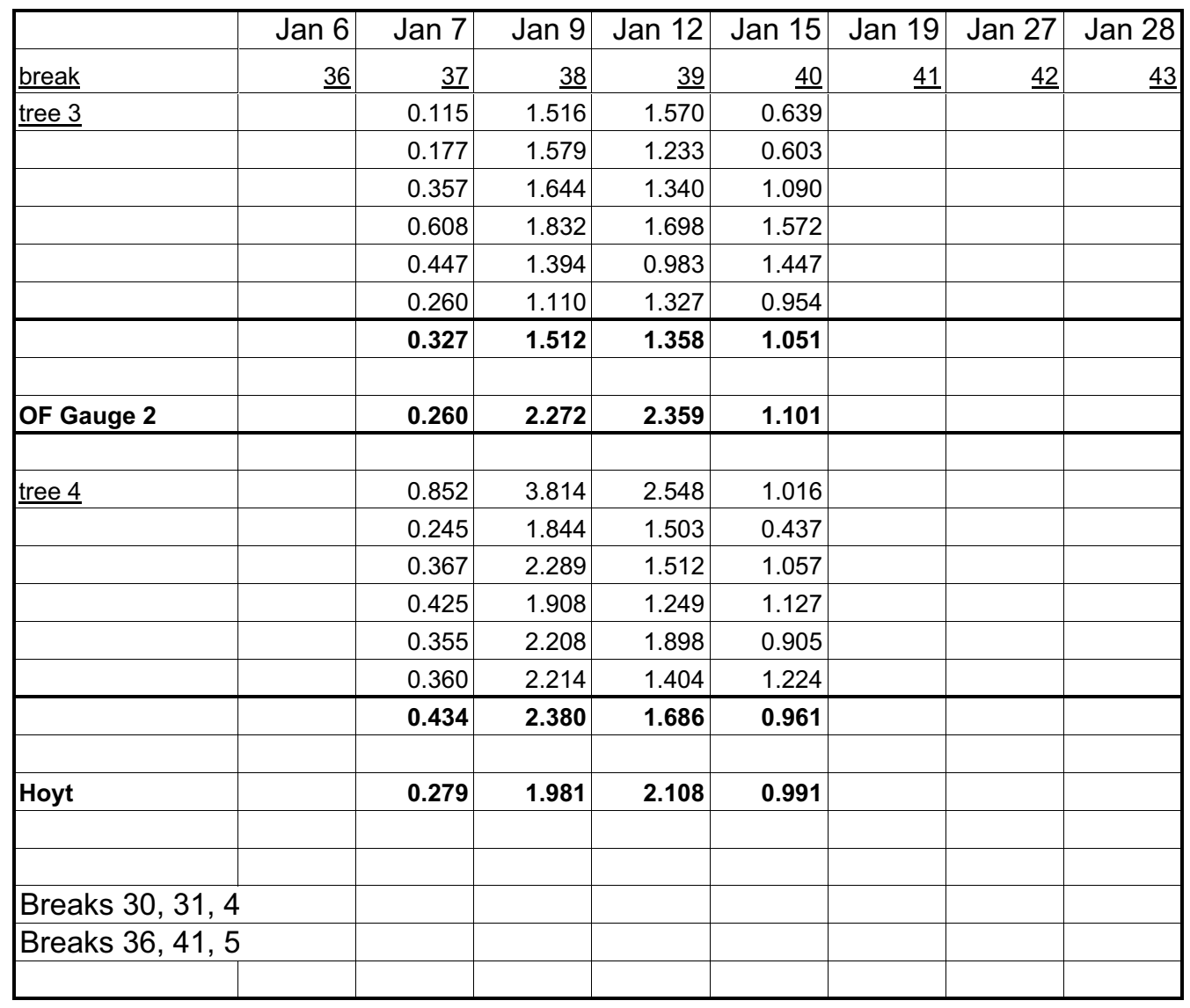




\begin{tabular}{|c|c|c|c|c|c|c|c|c|}
\hline \multicolumn{9}{|c|}{ Appendix A: } \\
\hline & Feb 1 & Feb 3 & Feb 8 & Feb 9 & Feb 10 & Feb 14 & Feb 21 & Feb 25 \\
\hline break & $\underline{44}$ & $\underline{45}$ & $\underline{46}$ & $\underline{47}$ & $\underline{48}$ & $\underline{49}$ & $\underline{50}$ & $\underline{51}$ \\
\hline \multirow[t]{7}{*}{ tree 1} & & 2.505 & 1.294 & & 0.005 & 0.000 & 0.000 & \\
\hline & & 3.081 & 1.376 & 0.264 & 0.004 & 0.000 & 0.000 & \\
\hline & & 1.412 & 1.862 & 0.366 & 0.002 & 0.000 & 0.000 & \\
\hline & & 1.472 & & 0.603 & 0.002 & 0.000 & 0.000 & \\
\hline & & 0.989 & 1.224 & 0.434 & 0.005 & 0.000 & 0.000 & \\
\hline & & 1.072 & & 0.447 & 0.007 & 0.000 & 0.000 & \\
\hline & & 1.755 & 1.439 & 0.423 & 0.004 & 0.000 & 0.000 & \\
\hline & & & & & & & & \\
\hline \multirow{7}{*}{$\underline{\underline{\text { tree } 2}}$} & & 2.368 & 1.304 & 0.304 & 0.007 & 0.000 & 0.000 & \\
\hline & & 1.752 & 1.470 & 0.229 & 0.004 & 0.004 & 0.000 & \\
\hline & & 1.499 & 1.928 & 0.585 & 0.007 & 0.031 & 0.000 & \\
\hline & & 1.501 & 1.358 & 0.447 & 0.005 & 0.000 & 0.000 & \\
\hline & & 2.075 & 1.082 & 0.302 & 0.007 & 0.000 & 0.000 & \\
\hline & & 2.253 & 1.127 & 0.405 & 0.004 & 0.007 & 0.000 & \\
\hline & & 1.908 & 1.378 & 0.378 & 0.006 & 0.007 & 0.000 & \\
\hline OF Gauge 1 & & 2.532 & 2.899 & 0.720 & 0.056 & 0.308 & 0.094 & \\
\hline \multirow{8}{*}{ tree 5} & & & & & & & & \\
\hline & & 4.851 & 1.490 & 0.523 & 0.018 & 0.050 & 0.009 & \\
\hline & & 1.840 & 1.127 & 0.423 & 0.007 & 0.051 & 0.012 & \\
\hline & & 1.912 & 2.878 & 1.197 & 0.025 & 0.090 & 0.011 & \\
\hline & & 2.038 & 1.407 & 0.457 & 0.011 & 0.090 & 0.005 & \\
\hline & & 1.858 & 1.501 & 0.563 & 0.016 & 0.075 & 0.007 & \\
\hline & & 2.113 & 1.251 & 0.447 & 0.009 & 0.080 & 0.005 & \\
\hline & & 2.435 & 1.609 & 0.602 & 0.014 & 0.073 & 0.008 & \\
\hline \multirow[t]{8}{*}{ tree 6} & & 2.109 & 1.068 & 0.534 & 0.007 & 0.028 & 0.002 & \\
\hline & & 1.760 & 1.118 & 0.449 & 0.005 & 0.039 & 0.002 & \\
\hline & & 2.151 & 1.833 & 0.673 & 0.021 & 0.099 & 0.011 & \\
\hline & & & 1.379 & 0.535 & 0.009 & 0.036 & 0.000 & \\
\hline & & 2.003 & 1.665 & 0.650 & 0.012 & 0.078 & 0.003 & \\
\hline & & 2.174 & 1.532 & 0.704 & 0.007 & 0.049 & 0.004 & \\
\hline & & 2.040 & 1.432 & 0.591 & 0.010 & 0.055 & 0.004 & \\
\hline & & & & & & & & \\
\hline
\end{tabular}




\begin{tabular}{|c|c|c|c|c|c|c|c|c|}
\hline & Feb 1 & Feb 3 & Feb 8 & Feb 9 & Feb 10 & Feb 14 & Feb 21 & Feb 25 \\
\hline break & $\underline{44}$ & $\underline{45}$ & $\underline{46}$ & $\underline{47}$ & $\underline{48}$ & $\underline{49}$ & $\underline{50}$ & $\underline{51}$ \\
\hline \multirow[t]{7}{*}{ tree 3} & & 1.889 & 1.277 & 0.390 & 0.005 & 0.103 & 0.028 & \\
\hline & & 1.845 & 1.383 & 0.514 & 0.005 & 0.009 & 0.000 & \\
\hline & & 2.167 & & 0.769 & 0.007 & 0.014 & & \\
\hline & & 2.055 & & 0.840 & 0.018 & 0.036 & 0.000 & \\
\hline & & 1.778 & 1.644 & 0.661 & 0.007 & 0.014 & 0.000 & \\
\hline & & 1.388 & 1.388 & 0.572 & 0.003 & 0.082 & 0.002 & \\
\hline & & 1.853 & 1.423 & 0.624 & 0.008 & 0.043 & 0.006 & \\
\hline OF Gauge 2 & & 2.449 & & 0.633 & 0.043 & 0.338 & 0.082 & \\
\hline \multirow[t]{7}{*}{ tree 4} & & 4.442 & 2.540 & 0.981 & 0.010 & 0.002 & 0.000 & \\
\hline & & 2.202 & 1.040 & 0.341 & 0.003 & 0.002 & 0.000 & \\
\hline & & 2.429 & 1.590 & 0.577 & 0.005 & 0.054 & 0.000 & \\
\hline & & 2.099 & 1.500 & 0.598 & 0.005 & 0.038 & 0.000 & \\
\hline & & 3.166 & 1.437 & 0.621 & 0.009 & 0.007 & 0.000 & \\
\hline & & 2.665 & 1.503 & 0.648 & 0.005 & 0.068 & 0.000 & \\
\hline & & 2.834 & 1.602 & 0.628 & 0.006 & 0.029 & 0.000 & \\
\hline Hoyt & & 2.311 & 2.515 & 0.610 & 0.025 & 0.356 & 0.051 & \\
\hline \multicolumn{9}{|c|}{ Breaks 30, 31, 4} \\
\hline \multicolumn{9}{|c|}{ Breaks 36, 41, 5} \\
\hline & & & & & & & & \\
\hline
\end{tabular}




\begin{tabular}{|c|c|c|c|c|c|c|c|c|}
\hline \multicolumn{9}{|c|}{ Appendix A: } \\
\hline & Mar 1 & Mar 2 & Mar 4 & Mar 8 & Mar 11 & Mar 13 & Mar 15 & Mar 16 \\
\hline break & $\underline{52}$ & $\underline{53}$ & $\underline{54}$ & $\underline{55}$ & $\underline{56}$ & $\underline{57}$ & $\underline{58}$ & $\underline{59}$ \\
\hline \multirow[t]{7}{*}{$\overline{\text { tree } 1}$} & 0.005 & 0.000 & & 0.509 & 0.002 & 0.929 & 0.125 & \\
\hline & 0.016 & 0.000 & & 0.361 & 0.005 & 0.827 & 0.158 & \\
\hline & & 0.000 & & 0.500 & 0.032 & 0.983 & 0.268 & \\
\hline & 0.067 & 0.000 & & 0.913 & 0.028 & 1.126 & 0.355 & \\
\hline & 0.028 & 0.000 & & 0.546 & 0.017 & 0.781 & 0.225 & \\
\hline & 0.043 & 0.002 & & 0.679 & 0.014 & 0.876 & 0.268 & \\
\hline & 0.032 & 0.000 & & 0.585 & 0.017 & 0.920 & 0.233 & \\
\hline & & & & & & & & \\
\hline \multirow[t]{8}{*}{$\underline{\underline{\text { tree } 2}}$} & 0.020 & 0.000 & & 0.643 & 0.014 & 1.001 & 0.277 & \\
\hline & 0.004 & 0.002 & & 0.458 & 0.002 & 1.135 & 0.123 & \\
\hline & 0.031 & 0.002 & & 1.353 & 0.117 & 1.188 & 0.667 & \\
\hline & 0.045 & 0.002 & & 0.357 & 0.025 & 0.652 & 0.250 & \\
\hline & 0.023 & 0.000 & & 0.639 & 0.012 & 1.100 & 0.142 & \\
\hline & 0.062 & 0.002 & & 0.563 & 0.039 & 1.056 & 0.255 & \\
\hline & 0.031 & 0.001 & & 0.669 & 0.035 & 1.022 & 0.286 & \\
\hline & & & & & & & & \\
\hline \multirow[t]{2}{*}{ OF Gauge 1} & 0.385 & 0.272 & & 1.116 & 0.457 & 1.622 & 1.431 & \\
\hline & & & & & & & & \\
\hline \multirow[t]{7}{*}{ tree 5} & 0.160 & 0.035 & & 1.046 & 0.186 & 1.215 & 0.709 & \\
\hline & 0.088 & 0.018 & & 0.625 & 0.100 & 1.144 & 0.423 & \\
\hline & 0.238 & 0.060 & & 1.241 & 0.266 & 1.540 & 1.074 & \\
\hline & 0.121 & 0.048 & & 1.115 & 0.121 & 0.923 & 0.731 & \\
\hline & 0.161 & 0.038 & & 0.947 & 0.175 & 1.126 & 0.661 & \\
\hline & 0.107 & 0.030 & & 1.090 & 0.127 & 0.911 & 0.679 & \\
\hline & 0.146 & 0.038 & & 1.011 & 0.163 & 1.143 & 0.713 & \\
\hline & & & & & & & & \\
\hline \multirow[t]{8}{*}{ tree 6} & 0.124 & 0.015 & & 0.620 & 0.096 & 1.257 & 0.491 & \\
\hline & 0.095 & 0.018 & & 0.880 & 0.106 & 1.056 & 0.475 & \\
\hline & 0.181 & 0.039 & & 0.926 & 0.187 & 1.356 & 0.739 & \\
\hline & 0.116 & 0.013 & & 0.898 & 0.098 & 0.934 & 0.481 & \\
\hline & 0.139 & 0.029 & & 0.997 & 0.163 & 1.067 & 0.703 & \\
\hline & 0.136 & 0.026 & & 1.003 & 0.192 & 1.268 & 0.599 & \\
\hline & 0.132 & 0.023 & & 0.887 & 0.140 & 1.156 & 0.581 & \\
\hline & & & & & & & & \\
\hline
\end{tabular}




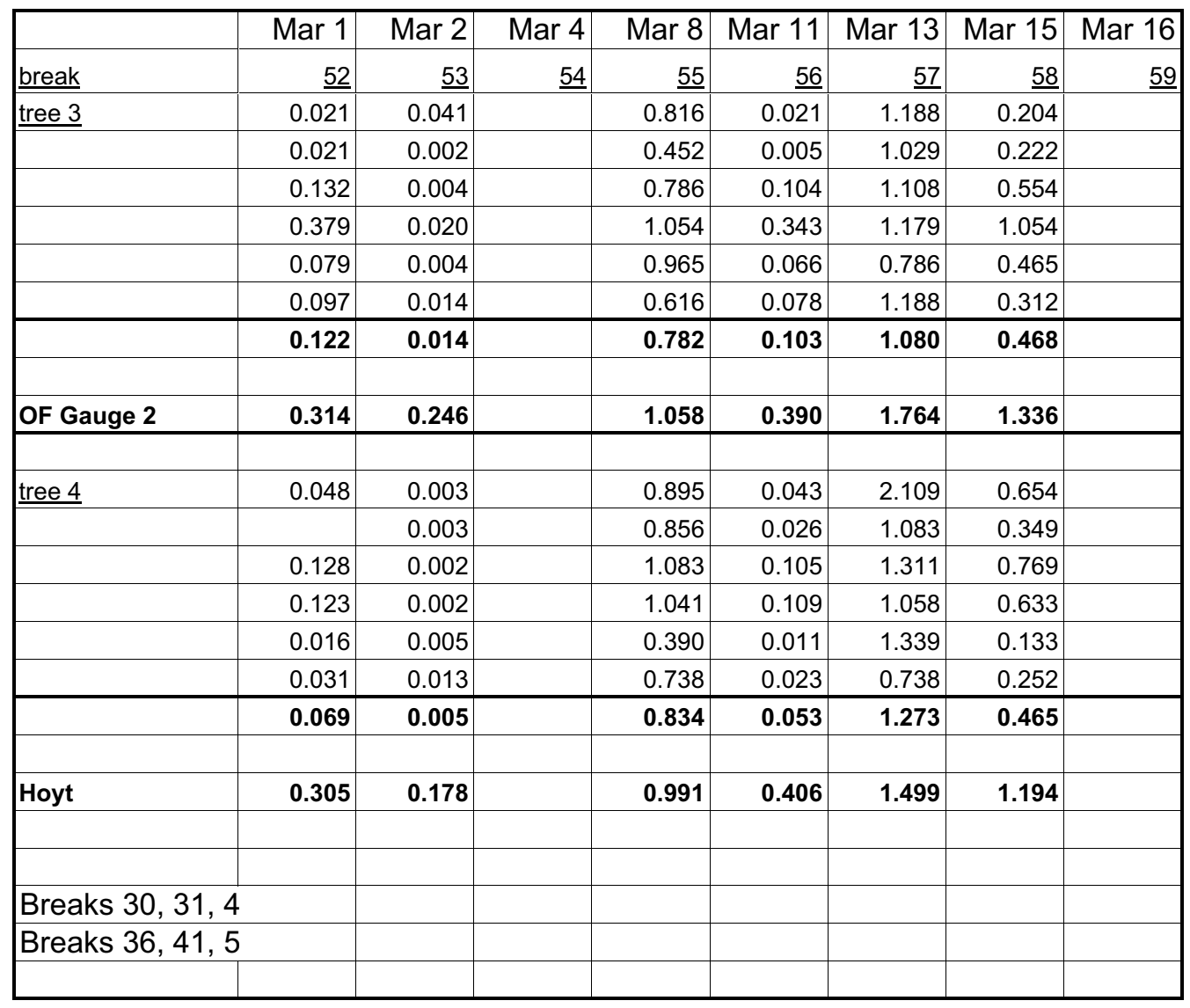




\begin{tabular}{|c|c|c|c|c|c|c|}
\hline \multicolumn{7}{|c|}{ Appendix A: } \\
\hline & Mar 17 & Mar 18 & Mar 21 & Mar 24 & Mar 30 & \\
\hline break & $\underline{60}$ & $\underline{61}$ & $\underline{62}$ & $\underline{63}$ & $\underline{64}$ & \\
\hline \multirow[t]{7}{*}{ tree 1} & 0.009 & 0.983 & 0.073 & 0.107 & 0.902 & \\
\hline & 0.035 & 1.329 & 0.114 & 0.158 & 0.951 & \\
\hline & 0.170 & 0.947 & 0.109 & & & \\
\hline & 0.115 & 2.182 & 0.245 & 0.293 & 1.490 & \\
\hline & 0.043 & 1.422 & 0.127 & 0.165 & 0.711 & \\
\hline & 0.041 & 1.671 & 0.130 & 0.179 & 0.911 & \\
\hline & 0.069 & 1.422 & 0.133 & 0.180 & 0.993 & 35.259 \\
\hline \multirow[t]{7}{*}{ tree 2 } & 0.021 & 1.340 & 0.120 & 0.179 & 0.902 & \\
\hline & 0.007 & 1.030 & 0.079 & 0.114 & 0.968 & \\
\hline & 0.194 & 1.819 & 0.289 & 0.475 & 1.864 & \\
\hline & 0.059 & 1.787 & 0.143 & 0.214 & 1.170 & \\
\hline & 0.032 & 1.446 & 0.082 & 0.133 & 0.656 & \\
\hline & 0.067 & 1.444 & 0.144 & 0.202 & 0.810 & \\
\hline & 0.063 & 1.477 & 0.143 & 0.220 & 1.062 & 38.562 \\
\hline OF Gauge 1 & 0.477 & 1.755 & 0.870 & 1.062 & 3.043 & 63.743 \\
\hline \multirow[t]{7}{*}{ tree 5} & 0.213 & 1.738 & 0.326 & 0.443 & 1.703 & \\
\hline & 0.132 & 1.655 & 0.243 & 0.317 & 1.611 & \\
\hline & 0.306 & 6.593 & 0.669 & 0.748 & 3.134 & \\
\hline & 0.214 & 1.334 & 0.329 & 0.420 & 1.928 & \\
\hline & 0.209 & 2.082 & 0.348 & 0.393 & 1.769 & \\
\hline & 0.191 & 1.483 & 0.340 & 0.393 & 1.778 & \\
\hline & 0.211 & 2.481 & 0.376 & 0.453 & 1.987 & 49.886 \\
\hline \multirow[t]{7}{*}{ tree 6} & 0.124 & 2.109 & 0.329 & 0.362 & 1.894 & \\
\hline & & 1.514 & 0.204 & 0.299 & 1.250 & \\
\hline & 0.226 & 2.020 & 0.398 & 0.468 & 2.113 & \\
\hline & 0.151 & 2.050 & 0.239 & 0.317 & 1.705 & \\
\hline & 0.222 & 1.839 & 0.324 & 0.416 & 1.908 & \\
\hline & 0.199 & 2.245 & 0.299 & 0.370 & 1.928 & \\
\hline & 0.184 & 1.963 & 0.299 & 0.372 & 1.800 & 44.339 \\
\hline & & & & & & \\
\hline
\end{tabular}




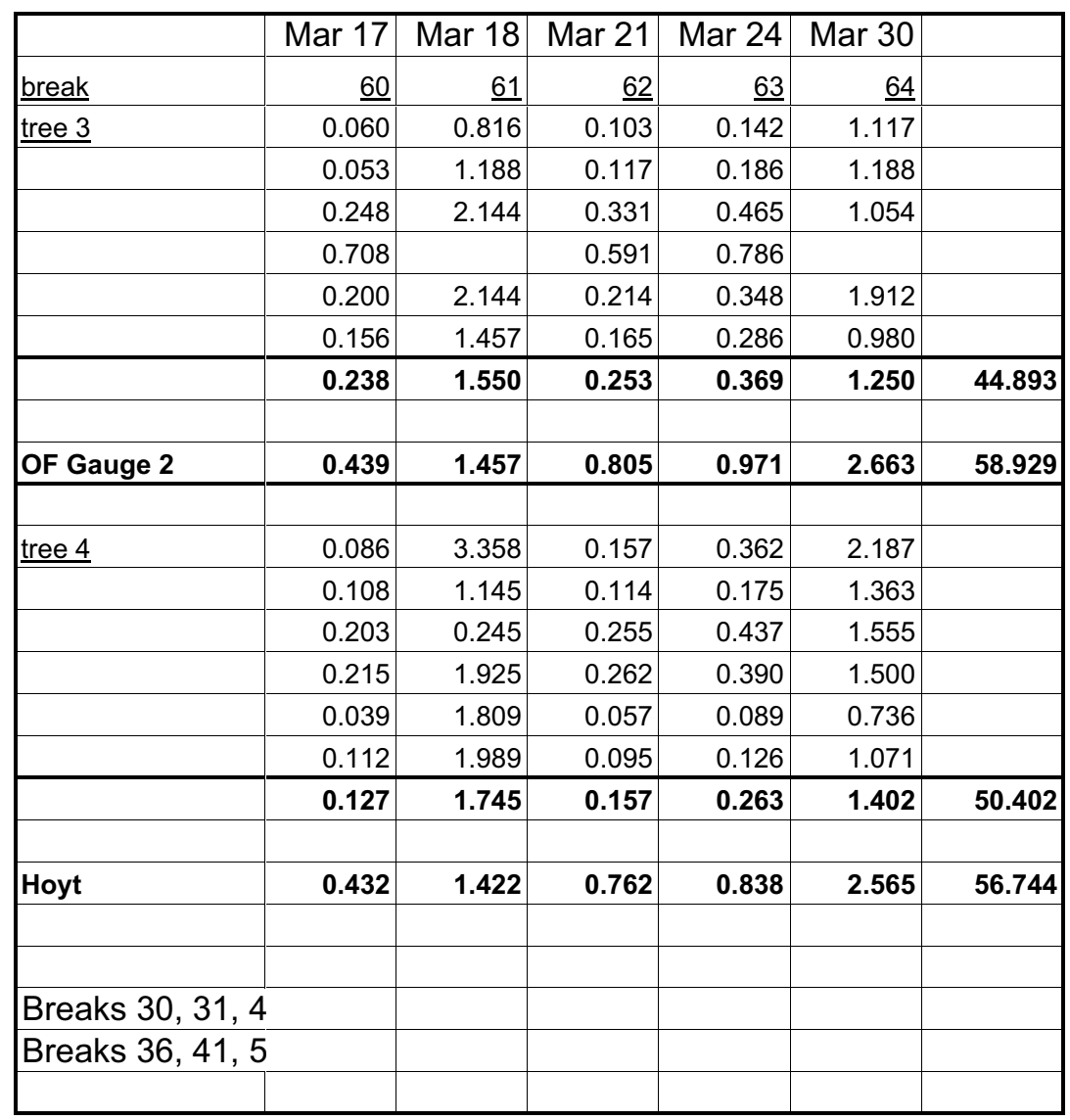




\section{Appendix B: Raingauge Comparison}

My study period lasted from 16Nov2007 to 30Mar2008. Incident rainfall varied somewhat among my three sources of incident rainfall. The tipping-bucket gauges at Hoyt Arboretum and the City of Portland's HYDRA gauge operated moreor-less continuously over the length of the study. The raingauge at Hoyt recorded $66.2 \mathrm{~cm}$, while the HYDRA gauge recorded $69.7 \mathrm{~cm}$. The third source, the open-field buckets, were occasionally subjected to ice, snow, and vandalism. During that same period, 221 hours of rainfall were not available in the open-field gauge record. Openfield gauges recorded $65.6 \mathrm{~cm}$ (by tree 3 ) and $71.6 \mathrm{~cm}$ (by tree 2). For the purposes of comparison, I include the totals for the first two sources over the more limited time: the Hoyt raingauge recorded $62.2 \mathrm{~cm}$ of rainfall (about 24 inches), while the HYDRA gauge recorded $61.6 \mathrm{~cm}$ of rainfall.

I used both rainfall recorded by the Hoyt raingauge and rainfall recorded at the open-field gauges. The Hoyt raingauge data were essential for tracking rainfall intensity through minute-by-minute data recording, and also for providing other useful meteorological data. The incident values were comparable to those recorded at the HYDRA site, and somewhat smaller than those from my own open-field collectors. Of the two numbers I have given here for the Hoyt rainfall $(66.2 \mathrm{~cm}$ and $62.2 \mathrm{~cm}), \mathrm{I}$ have used the smaller value, since it mirrored the data gaps present in the field data.

I have also used the incident values collected at the open-field gauges. Because they were much closer to and more representative of the study sites, they 
likely much better reflected conditions at the study sites. Their larger incident rainfall totals translated into higher interception rates.

Interception calculated using Hoyt rainfall totals was somewhat lower for all trees (Figure 22). When using Hoyt rainfall, interception rates for open-grown trees (\#1-4) went from 45, 40, 24 and 15\% to 38, 32, 21, and 12\%. At closed-canopy trees, interception went from 22 and $30 \%$ to 12 and $22 \%$. Despite this difference, the Hoyt totals were still valuable for establishing context and I used them to compute rainfall intensity, to determine meteorological characteristics during the study period, and to make comparisons with historical airport data. Because these analyses were largely relative to each other, they should not be seen as affecting overall conclusions drawn regarding open-grown interception.

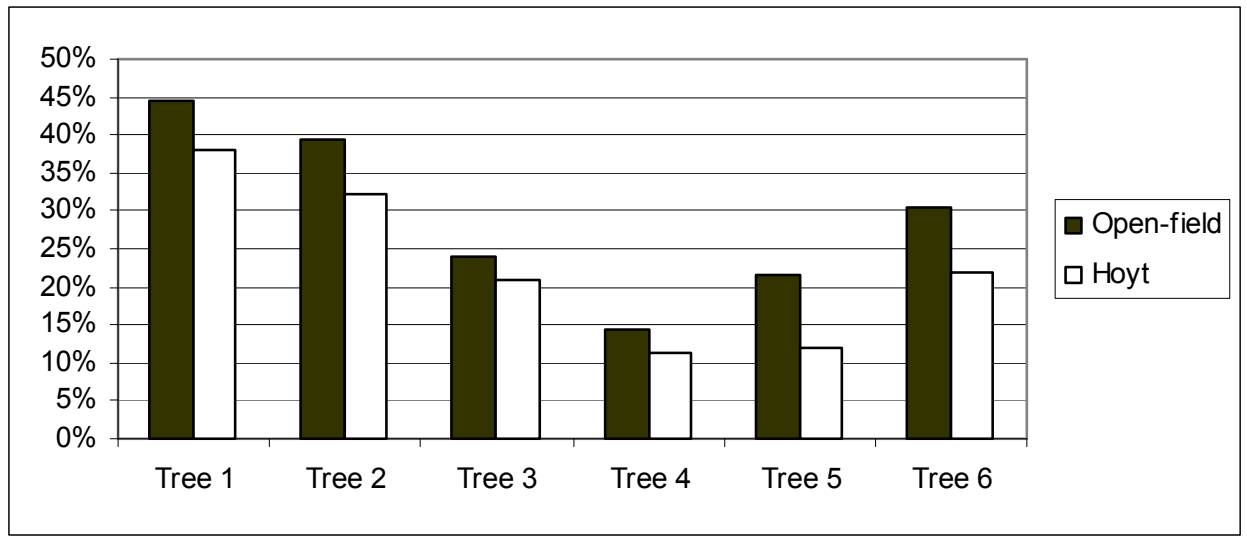

Figure 1. Determining Interception of Study Trees. A comparison of interception at each study tree: solid bars based computations on local, open-field incident totals; hollow bars based computations on the Hoyt Arboretum raingauge incident totals. Trees 1-4 were open-grown, while trees $5 \& 6$ were in a closed-canopy forest patch. 